\title{
Tissue Optics and Photonics: Biological Tissue Structures
}

\author{
V.V. Tuchin \\ Saratov State University, 83 Astrakhanskaya str., Saratov 410012, Russia \\ Institute of Precision Mechanics and Control RAS, 24 Rabochaya str., Saratov 410028, Russia \\ Samara State Aerospace University (SSAU), 34 Moskovskoye Shosse, Samara 443086, Russia \\ e-mail: tuchinvv@mail.ru
}

\begin{abstract}
This is the first section of the review-tutorial paper describing fundamentals of tissue optics and photonics mostly devoted to biological tissue structures and their specificity related to light interactions at its propagation in tissues. The next sections of the paper will describe light-tissue interactions caused by tissue dispersion, scattering, and absorption properties, including light reflection and refraction, absorption, elastic quasi-elastic and inelastic scattering. The major tissue absorbers and types of elastic scattering, including Rayleigh and Mie scattering, will be presented. (C) 2015 Samara State Aerospace University (SSAU).
\end{abstract}

Keywords: biophotonics; tissue optics; tissue structures.

Paper \#1991 received 2014.12.25; accepted for publication 2015.02.01; published online 2015.03.28.

\section{References}

1. R. R. Anderson, and J. A. Parrish, Optical properties of human skin in The Science of Photomedicine, eds. J. D. Regan, and J. A. Parrish, Plenum Press, NY, 147-194 (1982).

2. G. J. Müller, and D. H. Sliney (eds.) Dosimetry of Laser Radiation in Medicine and Biology, SPIE Inst. Adv. Opt. Techn. IS5, SPIE Press, Bellingham, WA. (1989),

3. A. V. Priezzhev, V. V. Tuchin, and L. P. Shubochkin, Laser Diagnostics in Biology and Medicine, Nauka, Moscow (1989).

4. K. Frank, and M. Kessler (eds.), Quantitative Spectroscopy in Tissue, pmi Verlag, Frankfurt am Main (1992).

5. A. J. Welch, and van M. J. C. Gemert (eds.), Tissue Optics, Academic, NY (1992).

6. S. L. Jacques, "Monte Carlo modeling of light transport in tissues," in Tissue Optics, A. J. Welch, and van M. C. J. Gemert (eds.), Academic, NY (1992).

7. G. Müller, B. Chance, R. Alfano, et al. (eds.), Medical Optical Tomography: Functional Imaging and Monitoring, SPIE Inst. Adv. Opt. Techn. IS11, SPIE Press, Bellingham, WA (1993).

8. V. V. Tuchin, Lasers light scattering in biomedical diagnostics and therapy, J. Laser Appl. 5 (2, 3), 43-60 (1993).

9. V. V. Tuchin (ed.), Selected Papers on Tissue Optics: Applications in Medical Diagnostics and Therapy, MS102, SPIE Press, Bellingham, WA (1994).

10. M. S. Patterson, "Noninvasive measurement of tissue optical properties: current status and future prospects" in Comments Mol. Cell. Biophys. 8, Gordon and Breach Sci. Publ. Inc., 387-417 (1995).

11. B. Chance, M. Cope, E. Gratton, N. Ramanujam, and B. Tromberg, Phase measurement of light absorption and scatter in human tissue, Rev. Sci. Instrum. 69(10), 3457-3481 (1998).

12. V. V. Tuchin, Light scattering study of tissues, Physics - Uspekhi 40 (5), 495-515 (1997).

13. O. Minet, G. Müller, and J. Beuthan (eds.), Selected Papers on Optical Tomography, Fundamentals and Applications in Medicine, MS147, SPIE Press, Bellingham, WA (1998).

14. V. V. Tuchin, Tissue Optics: Light Scattering Methods and Instruments for Medical Diagnosis, SPIE Tutorial Texts in Optical Engineering TT38, SPIE Press, Bellingham, WA (2000).

15. V. V. Tuchin (ed.), Handbook of Optical Biomedical Diagnostics, PM107, SPIE Press, Bellingham, WA (2002) (translated to Russian, Fizmatlit, Moscow, 2007, 2 vols.).

16. H.-P. Berlien, and G. J. Müller (eds.), Applied Laser Medicine, Springer-Verlag, Berlin (2003).

17. T. Vo-Dinh (ed.), Biomedical Photonics Handbook, CRC Press, Boca Raton (2003).

18. V. V. Tuchin (ed.), Coherent-Domain Optical Methods for Biomedical Diagnostics, Environmental and Material Science, vols. 1 \& 2, Kluwer Academic Publishers, Boston, Dordrecht, L. (2004). 
19. B. Wilson, V. Tuchin, and S. Tanev (eds.), Advances in Biophotonics, NATO Science Series I. Life and Behavioural Sciences, 369, IOS Press, Amsterdam (2005).

20. V. V. Tuchin, L. V. Wang, and D. A. Zimnyakov, Optical Polarization in Biomedical Applications, Springer, NY (2006).

21. V. V. Tuchin, Optical Clearing of Tissues and Blood, PM 154, SPIE Press, Bellingham, WA (2006).

22. A. Kishen, and A. Asundi (eds.), Photonics in Dentistry. Series of Biomaterials and Bioengineering, Imperial College Press, London (2006).

23. V. V. Tuchin, Tissue Optics: Light Scattering Methods and Instruments for Medical Diagnosis, 2nd ed., PM 166, SPIE Press, Bellingham, WA (2007) (translated to Russian, Fizmatlit, Moscow, 2012).

24. L. V. Wang, and H.-I. Wu, Biomedical Optics: Principles and Imaging, Wiley-Intersience, Hoboken, NJ (2007).

25. V. V. Tuchin, A clear vision for laser diagnostics, IEEE J. Select. Tops. Quant. Electr. 13(6), 1621-1628 (2007).

26. R. Splinter, and B. A. Hooper, An Introduction to Biomedical Optics, CRC Press, Taylor \& Francis Group, NY, London (2007).

27. V. V. Tuchin (ed.), Handbook of Optical Sensing of Glucose in Biological Fluids and Tissues, CRC Press, Taylor \& Francis Group, London (2009).

28. M. F. Yang, V. V. Tuchin, and A. N. Yaroslavsky, "Principles of light skin interactions" in Light-Based Therapies for Skin of Color, E. D. Baron (ed.), Springer, London, 1-45 (2009).

29. G. B. Altshuler, and V. V. Tuchin, "Physics behind the light-based technology: Skin and hair follicle interactions with light" in Cosmetic Applications of Laser \& Light-Based Systems, G. Ahluwalia (ed.), William Andrew, Inc., Norwich, NY, 49-109 (2009).

30. V. V. Tuchin, "Optical spectroscopy of biological materials," Chapter 16 in Encyclopedia of Applied Spectroscopy, D. L. Andrews (ed.), Wiley-VCH Verlag GmbH \& Co. KGaA, Weinheim, 555-626 (2009).

31. E. D. Baron (ed.), Light-Based Therapies for Skin of Color, Springer, London (2009).

32. G. Ahluwalia (ed.), Light Based Systems for Cosmetic Application, William Andrew, Norwich (2009).

33. K.-E. Peiponen, R. Myllylä, and A. V. Priezzhev, Optical Measurement Techniques, Innovations for Industry and the Life Science, Springer-Verlag, Berlin, Heidelberg (2009).

34. P. Zakharov, and F. Scheffold, Advances in dynamic light scattering techniques, in Light Scattering Reviews 4: Single Light Scattering and Radiative Transfer, A. A. Kokhanovsky (ed.), Springer, Heidelberg, 433-468 (2009).

35. A. Wax, and V. Backman (eds.), Biomedical Applications of Light Scattering, McGraw-Hill, NY (2010).

36. V. V. Tuchin (ed.), Handbook of Photonics for Biomedical Science, CRC Press, Taylor \& Francis Group, London (2010).

37. M. M. Nazarov, A. P. Shkurinov, V. V. Tuchin, and X.-C. Zhang, Terahertz tissue spectroscopy and imaging, Chapter 23 in Handbook of Photonics for Biomedical Science, V. V. Tuchin (ed.), CRC Press, Taylor \& Francis Group, London, 591-617 (2010).

38. F. S. Pavone (ed.), Laser Imaging and Manipulation in Cell Biology, Wiley-VCH Verlag GmbH \& Co. KGaA, Weinheim (2010).

39. E. A. Genina, A. N. Bashkatov, and V. V. Tuchin, Tissue optical immersion clearing, Expert Rev. Med. Devices 7(6), 825-842 (2010).

40. V. V. Tuchin, Lasers and Fibre Optics in Biomedical Science, 2nd ed., Fizmatlit, Moscow (2010).

41. A. P. Dhawan, B. D'Alessandro, and X. Fu, "Optical Imaging Modalities for Biomedical Applications," IEEE Reviews in Biomedical Engineering 3, 69-92 (2010).

42. X.-C. Zhang, and J. Xu, Introduction to THz Wave Photonics, Springer, NY (2010).

43. E. A. Genina, A. N. Bashkatov, K. V. Larin, and V. V. Tuchin, "Light-tissue interaction at optical clearing," in Laser Imaging and Manipulation in Cell Biology, F. S. Pavone (ed.) (Wiley-VCH Verlag GmbH \& Co. KGaA, Weinheim), 115-164 (2010).

44. A. N. Bashkatov, E. A. Genina, and V. V. Tuchin, Optical properties of skin, subcutaneous, and muscle tissues: a review, J. Innov. Opt. Health Sci. 4(1), 9-38 (2011).

45. D. A. Boas, C. Pitris, and N. Ramanujam (eds.), Handbook of Biomedical Optics, CRC Press, Taylor \& Francis Group, London (2011).

46. V. V. Tuchin (ed.), Advanced Optical Cytometry: Methods and Disease Diagnoses, Wiley-VCH Verlag GmbH \& Co. KGaA, Weinheim (2011).

47. V. V. Tuchin, Dictionary of Biomedical Optics and Biophotonics, SPIE Press, Bellingham, WA (2012).

48. K. V. Larin, M. G. Ghosn, A. N. Bashkatov, E. A. Genina, N. A. Trunina, and V. V. Tuchin, "Optical clearing for OCT image enhancement and in-depth monitoring of molecular diffusion,” IEEE J. Select. Tops. Quant. Electr. 18 (3) 1244-1259 (2012).

49. V. V. Tuchin (ed.), Coherent-Domain Optical Methods: Biomedical Diagnostics, Environmental Monitoring and Material Science, Berlin, Heidelberg, N. Y., Springer-Verlag, 2nd ed., 2 vols (2013). 
50. R. K. Wang, and V. V. Tuchin, “Optical coherence tomography: light scattering and imaging enhancement," in Coherent-Domain Optical Methods: Biomedical Diagnostics, Environmental Monitoring and Material Science. V. 1, 2nd edition, V. V. Tuchin (ed.), Springer-Verlag, Berlin, Heidelberg, NY, 665-742 (2013).

51. A. Douplik, G. Saiko, I. Schelkanova, and V. V. Tuchin, "The response of tissue to laser light," in Lasers for Medical Applications: Diagnostics, Therapy and Surgery, H. Jelinkova (ed.), Woodhead Publishing, Ltd., Cambridge, pp.47-109 (2013).

52. D. Zhu, K. V. Larin, Q. Luo, and V. V. Tuchin, "Recent progress in tissue optical clearing," Laser Photonics Rev. 7(5), 732-757 (2013).

53. D. Zhu, Q. Luo, and V. V. Tuchin, “Tissue Optical Clearing," in Advanced Biophotonics: Tissue Optical Sectioning, R. K. Wang, and V. V. Tuchin (eds.), CRC Press, Taylor \& Francis Group, Boca Raton, London, NY, 621-672 (2013).

54. J. Wang, Y. Zhang, P. Li, Q. Luo, and D. Zhu, "Review: Tissue Optical Clearing Window for Blood Flow Monitoring (Invited Paper)," IEEE J. Select. Tops Quant. Electr. 20 (2), 6801112-1-12 (2014).

55. O. Nadiarnykh, and P. J. Campagnola, "SHG and optical clearing," in Second Harmonic Generation Imaging, F. S. Pavone, and P. J. Campagnola (eds.), CRC Press, Taylor \& Francis Group, Boca Raton, London, NY, 169-189 (2014).

56. F. S. Pavone, and P. J. Campagnola (eds.), Second Harmonic Generation Imaging, CRC Press, Taylor \& Francis Group, Boca Raton, London, NY (2014).

57. T. Vo-Dinh (ed.), Biomedical Photonics Handbook, 2nd ed., CRC Press, Boca Raton (2014).

58. V. V. Tuchin, Tissue Optics: Light Scattering Methods and Instruments for Medical Diagnosis, SPIE Press, PM 254, 3rd ed., SPIE Press, Bellingham, WA (2015).

59. P. Prasad, Introduction to Biophotonics. Wiley-Interscience, Hoboken, NJ (2003).

60. L. Pavesi, Ph. M. Fauchet (eds.), Biophotonics (Biological and Medical Physics, Biomedical Engineering), Springer Verlag, Berlin, Heidelberg (2008).

61. J. Popp, V. Tuchin, A. Chiou, and S. H. Heinemann (eds.), Handbook of Biophotonics: Basics and Techniques, vol.1, Wiley-VCH Verlag GmbH \& Co. KGaA, Weinheim (2011).

62. J. Popp, V. V. Tuchin, A. Chiou, and S. H. Heinemann (eds.), Handbook of Biophotonics: Photonics for Health Care, vol. 2, WILEY-VCH Verlag GmbH \& Co. KGaA, Weinheim (2011).

63. J. Popp, V. V. Tuchin, A. Chiou, and S. H. Heinemann (eds.), Handbook of Biophotonics: Photonics in Pharmaceutics, Bioanalysis and Environmental Research, vol. 3, WILEY-VCH Verlag GmbH \& Co. KGaA, Weinheim (2012).

64. R. K. Wang, and V. V. Tuchin, Advanced Biophotonics: Tissue Optical Sectioning, CRC Press, Taylor \& Francis Group, London (2013).

65. A. Yariv, Quantum Electronics, John Wiley \& Sons, NY (1989).

66. F. H. Silver, Biological Materials: Structure, Mechanical Properties, and Modelling of Soft Tissues, New York Univ. Press, NY (1987).

67. F. A. Duck, Physical Properties of Tissue: A Comprehensive Reference Book, Academic, L. (1990).

68. T. B. Fitzpatrick, A. Z. Eisen, K. Wolff, I. M. Freedberg, and K. F. Austen (eds.), Dermatology in General Medicine, McGraw-Hill, NY (1993).

69. J. D. Bancroft, and A. Stevens (eds.), Theory and Practice of Histological Techniques, Churchill Livingstone, Edinburgh, NY (1990).

70. R. G. Kessel, Basic Medical Histology: The Biology of Cells, Tissues, and Organs, Oxford Univ. Press, NY (1998).

71. P. Agache, and P. Humbert (eds.), Measuring the Skin, Springer, Berlin, Heidelberg (2004).

72. T. A. Waigh, Applied Biophysics: Molecular Approach for Physical Scientists, John Wiley \& Sons Ltd, Chichester (2007).

73. I. P. Herman, Physics of the Human Body, Springer, Berlin, Heidelberg, NY (2007).

74. D. M. Maurice, "The cornea and sclera" in The Eye, H. Davson (ed.), 3rd ed., 1B, Academic Press, Orlando, $1-158$ (1984).

75. F. A. Bettelheim, "Physical basis of lens transparency" in The Ocular Lens: Structure, Function and Pathology, H. Maisel (ed.), Marcel-Dekker, NY, 265-300 (1985).

76. M. J. Hogan, J. A. Alvardo, and J. Weddel, Histology of the Human Eye, W. B. Sanders Co., Philadelphia (1971).

77. X. Wang, T. E. Milner, M. C. Chang, and J. S. Nelson, "Group refractive index measurement of dry and hydrated type I collagen films using optical low-coherence reflectometry,” J. Biomed. Opt. 1(2), 212-216 (1996).

78. L. Moss-Salentijn, and M. Hendricks-Klyvert, Dental and Oral Tissues, An Introduction, 3rd edition, Lea \& Febiger, Philadelphia, L. (1990).

79. R. L. McCally, and R. A. Farrell, "Light scattering from cornea and corneal transparency," in Noninvasive Diagnostic Techniques in Ophthalmology, B. R. Master (ed.), Springer-Verlag, NY, 189-210 (1990). 
80. R. A. Farrell, D. E. Freund, and R. L. McCally, "Research on corneal structure" in Johns Hopkins APL Techn. Digest 11, 191-199 (1990).

81. R. A. Farrell, and R. L. McCally, "Corneal transparency" in Principles and Practice of Ophthalmology, D. A. Albert, and F. A. Jakobiec (eds.), W. B. Saunders, Philadelphia, PA, 629-643 (2000).

82. Y. Kamai, and T. Ushiki, The three-dimensional organization of collagen fibrils in the human cornea and sclera, Invest. Ophthalmol. \& Visual Sci. 32, 2244-2258 (1991).

83. Y. Huang, and K. M. Meek, Swelling studies on the cornea and sclera: the effect of $\mathrm{pH}$ and ionic strength, Biophys. J. 77, 1655-1665 (1999).

84. O. Kostyuk, O. Nalovina, T. M. Mubard, J. W. Regini, K. M. Meek, A. J. Quantock, G. F. Elliott, and S. A. Hodson, "Transparency of the bovine corneal stroma at physiological hydration and its dependence on concentration of the ambient anion," J. Physiol. 543, 633-642 (2002).

85. K. M. Meek, S. Dennis, and S. Khan, "Changes in the refractive index of the stroma and its extrafibrillar matrix when the cornea swells,” Biophys. J. 85, 2205-2212 (2003).

86. H. Schaefer, and T. E. Redelmeier, Skin Barrier: Principles of Percutaneous Absorption, Karger, Basel (1996).

87. http://www.sportsci.org/encyc/adipose/adipose.html. December 17, 2014.

88. M. J. Costello, T. N. Oliver, and L. M. Cobo, "Cellular architecture in aged related human nuclear cataracts," Invest. Ophthal. \& Vis. Sci. 3(1), 2244-2258 (1992).

89. Y. Ozaki, "Medical application of Raman spectroscopy,” Appl. Spectrosc. Rev. 24(3), 259-312 (1988).

90. H. A. Linares, C. W. Kischer, M. Dobrkovsky, and D. L. Larson, "The histiotypic organization of the hypertrophic scar in humans," J. Invest. Dermatol. 59, 323-331 (1972).

91. P. Gong, R. A. McLaughlin, Y. M. Liew, P. R. T. Munro, F. M. Wood, and D. D. Sampson, "Assessment of human burn scars with optical coherence tomography by imaging the attenuation coefficient of tissue after vascular masking,” J. Biomed. Opt. 19(2), 021111-1-10 (2014).

92. N. Ugryumova, S. J. Matcher, and D. P. Attenburrow, "Measurement of bone mineral density via light scattering," Phys. Med. Biol. 49(3), 469-483 (2004).

93. S. Kaiplavil, A. Mandelis, and B. T. Amaechi, "Truncated-correlation photothermal coherence tomography of artificially demineralized animal bones: two- and three-dimensional markers for mineral loss monitoring," J. Biomed. Opt. 19(2), 026015-1-14 (2014).

94. G. Li, J. Yin, J. Gao, T. S. Cheng, N. J. Pavlos, C. Zhang, and M. H. Zheng, "Subchondral bone in osteoarthritis: insight into risk factors and microstructural changes Arthritis. Res. Ther. 15(6), 223-1-12 (2013).

95. S. J. Matcher, "A review of some recent developments in polarization-sensitive optical imaging techniques for the study of articular cartilage," J. Appl. Phys. 105, 102041 (2009).

96. M. Sivakumar, V. Oliveira, S. Oliveira, J. Leitão, and R. Vilar, "Influence of tubule orientation on cone-shaped texture development in laser-ablated dentin," Lasers Med. Sci. 21, 160-164 (2006).

97. V. V. Tuchin, and G. B. Altshuler, "Dental and oral tissue optics" in Photonics in Dentistry. Series of Biomaterials and Bioengineering, A. Kishen and A. Asundi (eds.) Imperial College Press, L., 245-300 (2006).

98. B. M. Eley, and J. D. Manson, Periodontics, 5th ed. Elsevier Ltd., Philadelphia (2004).

99. N. A. Trunina, V. V. Lychagov, and V. V. Tuchin, "Study of water diffusion in human dentin by optical coherent tomography," Opt. Spectrosc. 109(2), 162-168 (2010).

100.P. O. Bagnaninchi, Y. Yang, M. Bonesi, G. Maffulli, C. Plelan, I. Meglinski, et al., "In-depth imaging and quantification of degenerative changes associated with Achilles ruptured tendons by polarizationsenstive optical coherence tomography," Phys. Med. Biol. 55, 3777-3787 (2010).

101.M. H. Steinberg, B. G. Forget, D. R. Higgs, and D. J. Weatherall (eds.), Disorders of Hemoglobin: Genetics, Pathophysiology, and Clinical Management, 2nd ed., Cambridge, Cambridge University Press (2009).

102.M. Fabry, and J. M. Old, "Laboratory methods for diagnosis and evaluation of hemoglobin disorders," Chapter 28 in Disorders of Hemoglobin: Genetics, Pathophysiology, and Clinical Management, M. H. Steinberg, B. G. Forget, D. R. Higgs, and D. J. Weatherall (eds.), Cambridge, Cambridge University Press, 656-686 (2009).

103. V. V. Tuchin, In vivo optical flow cytometry and cell imaging, Rivista Del Nuovo Cimento, 37(7), 375-416 (2014).

104.E. I. Galanzha, M. S. Kokoska, E. V. Shashkov, J.-W. Kim, V. V. Tuchin, and V. P. Zharov, "In vivo fiber photoacoustic detection and photothermal purging of metastasis targeted by nanoparticles in sentinel lymph nodes at single cell level," J. Biophoton. 2, 528-539 (2009).

105.S. A. Asher, and J. T. Baca, "Tear fluid photonic crystal contact lens noninvasive glucose sensors" in Handbook of Optical Sensing of Glucose in Biological Fluids and Tissues, V. V. Tuchin (ed.), Taylor \& Francis Group LLC, CRC Press, 267-297 (2009). 


\section{Contents}

1 Introduction

2 Biological tissue structures

2.1 General definitions and characteristics

2.2 Soft tissues

2.3 Hard tissues

2.4Tissue structural anisotropy

2.5 Blood, lymph and other bioliquids

2.6 Conclusion

\section{Introduction}

In this review paper, fundamentals of tissue optics and photonics are discussed. Basic principles of light-tissue interaction and light beam propagation in weakly and strongly scattering tissues are considered. The discussion of different optical phenomena in tissues in one paper could be helpful for understanding of interrelations between different optical modalities beneficial for biomedical diagnostics and treatment. Currently there are available a plenty of literature describing tissue optics and biomedical applications of optical technologies, which can be recommended for further reading [1-58]. Biophotonics as a science and technology use tissue optics as basics for designing innovative optical diagnostical and treatment technologies [59-64].

The electromagnetic wave spectrum presented schematically in Fig. 1 shows wavelength range from the very short ones of gamma rays to the very long of radio waves, where only very small interval belongs to visible light from 400 to $780 \mathrm{~nm}$. Physicians who apply light in phototherapy or vision science classify the light spectrum (i.e., from $100 \mathrm{~nm}$ to $1000 \mu \mathrm{m}$ ) basing on the major mechanism of light interaction with biological cells or tissues. In particular, spectral ranges are classified as ultraviolet (UV) light (UVC, 100-280 nm; UVB, 280-315 $\mathrm{nm}$; and UVA, 315-400 nm); visible (400-780 nm); and infrared (IR) ligh (IRA, 780-1400 $\mathrm{nm}$; IRB, 1400-3000 nm; and IRC, 3-1000 $\mu \mathrm{m})$. However, physicists who consider light's interaction with and propagation in abiological media (atmosphere, ocean, etc.) classify light spectrum as UV (100-400 $\mathrm{nm})$, visible (400-800 nm), near IR (NIR) (800-2500 $\mathrm{nm})$, middle IR (MIR) $(2.5-50 \mu \mathrm{m})$, and far IR (FIR) $(50-2000 \mu \mathrm{m})$. Presently, as light is more and more widely and effectively used in medicine, both classifications and terminologies are on use in the biomedical optics and biophotonics.

For example, due to great importance of the near infrared range for tissue spectroscopy and imaging, the abbreviation NIR is often used now by medical doctors. A current interest and future perspective of the terahertz range of electromagnetic radiation for biomedical applications spread the light wavelength range classification used in medicine to the $2000 \mu \mathrm{m}$ that used by physicists.

To characterize the efficiency of light interaction with biological tissue (inducing a photochemical reaction, temperature increase, evaporation, thermal mechanical breaking, etc.) besides choosing the wavelength of light, its energetic parameters are also important. Two major parameters are typically used: energy and power. Energy is the ability of light to produce some work; energy $E$ is measured in joules $(\mathrm{J})$. Power is the rate of delivery of energy; it is normally measured in watts $(\mathrm{W})$ (i.e., joules per second $(\mathrm{J} / \mathrm{s})$ ).

At light interaction with tissues, produced photophysical, photochemical, or photobiological effects depend on energy density and/or power density that are provided within the target area. Energy density or fluence is the energy of the light wave that propagates through a unit area which is perpendicular to the direction of propagation of the light wave. Fluence is measured in $\mathrm{J} / \mathrm{m}^{2}$ or $\mathrm{J} / \mathrm{cm}^{2}$ and power density or intensity is measured in $\mathrm{W} / \mathrm{m}^{2}$ or $\mathrm{W} / \mathrm{cm}^{2}$. The relationship between fluence $(F)$ and intensity $(I)$ is given by:

$$
F=I \times \tau_{p}
$$

where $\tau_{p}$ is the length of pulse (pulsewidth) or exposure time.

In inhomogeneous light scattering media to which tissues belong, the following parameter is often used: fluence rate (or total radiant energy fluence rate), that is, the sum of the radiance over all angles at a point $\bar{r}$; the quantity that is typically measured in irradiated tissues $\left(\mathrm{W} / \mathrm{m}^{2}\right.$ or $\left.\mathrm{W} / \mathrm{cm}^{2}\right)$ and commonly called "intensity" or "quantum flux."

In general, a light beam is a slender stream of light. Often the user needs a collimated beam - a beam of light in which all rays are parallel to each other and the wavefront is a plane. Such a beam, in some cases, can be provided automatically by using an appropriate laser or can be formed by special optics (with possible significant loss of light energy) using conventional light sources such as lamps.

Typically, laser beam has a Gaussian shape for the transverse intensity profile. If the intensity at the centre of the beam is $I(0, z)$ for a distance $z$ apart the position of the laser beam "waist" (the narrowest part of a beam), the formula for a Gaussian beam is [65]

$$
I(r, z)=I(0, z) \exp \left\{-2\left(\frac{r}{w_{b}(z)}\right)^{2}\right\}
$$

where $r$ is the radial distance from the axis and $w_{b}(z)$ is the beam radius at distance $z$ from laser counted from the position of the beam "waist". A single-mode fibre with a core diameter of several microns also creates a Gaussian beam at its output.

The initial beam divergence of the light source is important for a light beam focusing on the target and for controlling the light spot diameter. The radius of the beam in the focal plane of the lens with a focal length $f$ is given by:

$$
w=f \times \theta,
$$




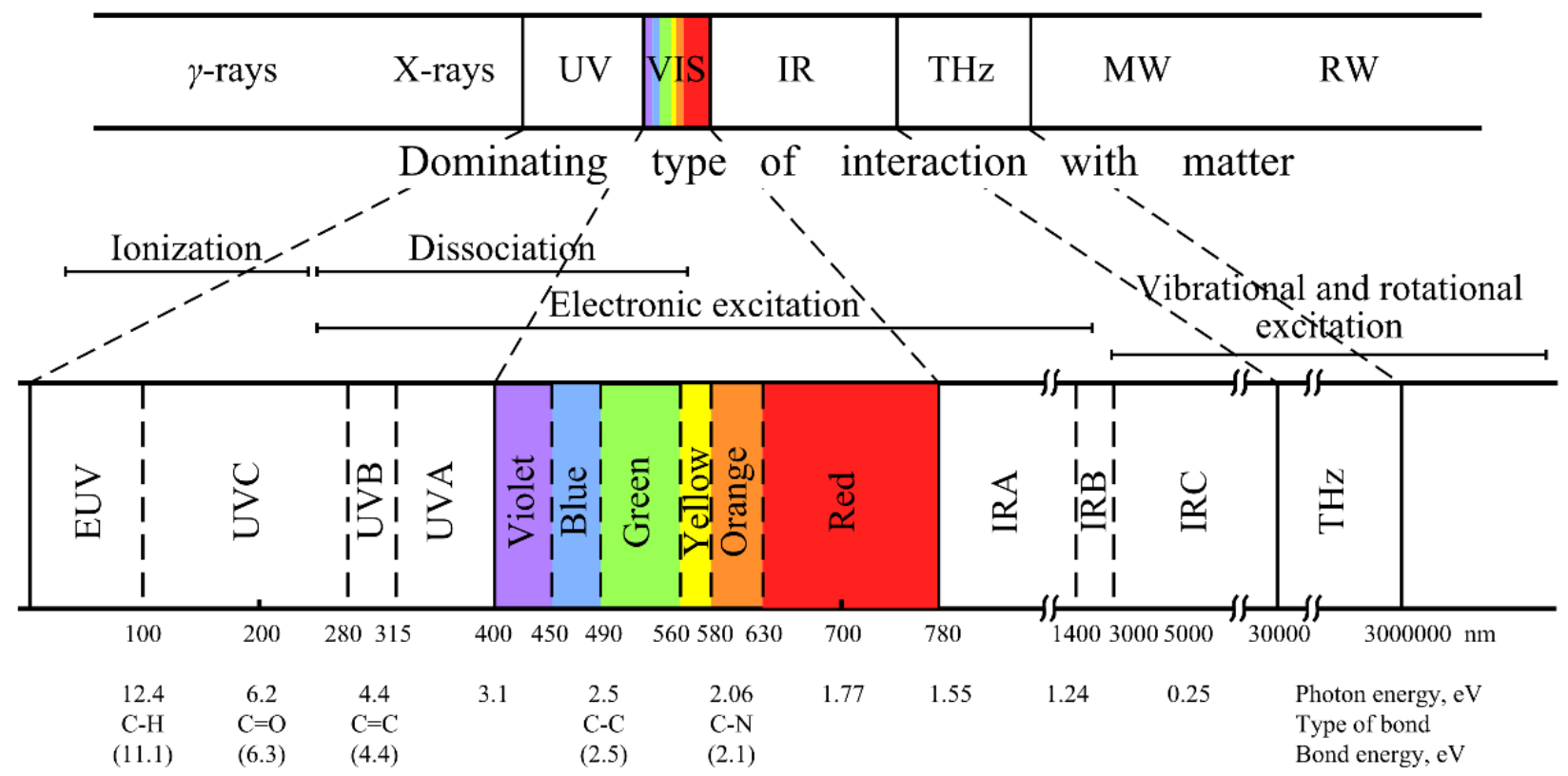

Fig. 1.1 Electromagnetic spectrum and types of interaction with matter (UV - ultraviolet, EUV - extreme UV, VIS visible, IR - infrared, MW - microwaves, THz - terahertz, RW - radio waves). Modified from [40].

where $\theta$ is the beam divergence.

Single mode lasers or single mode fibres have a minimal beam divergence and can provide minimal light spot size; for a single mode laser (TEM ${ }_{00}$-mode)

$$
\theta \cong \lambda / \pi w(0)
$$

where $w(0)$ is the laser beam radius in its "waist." Minimal light spot size in the focal plane of the aberration free optical system can be close to the wavelength $\lambda$. For enough far distance from the laser, $z>>\pi w^{2}(0) / \lambda$, laser beam radius is defined by a simple formula:

$$
w(z) \cong z \theta
$$

Evidently, light-tissue interaction depends on temporal parameters of the light, whether it is continuous wave $(\mathrm{CW})$ or pulse. Pulsed light can be produced as a single pulse of duration $\tau_{p}$ (pulsewidth), measured in seconds (s), or as successive trains of pulses with some repetition frequency (rate) $f_{p}$, measured in hertz $\left(\mathrm{s}^{-1}\right)$. Lamps can typically generate light pulses $\tau_{p}$ up to nanosecond (ns) $\left(10^{-9} \mathrm{~s}\right.$ ), and only lasers can generate more shorter pulses, in picosecond (ps) $\left(10^{-12} \mathrm{~s}\right)$ or femtosecond (fs) $\left(10^{-15} \mathrm{~s}\right)$ ranges with a high repetition rate $f_{p}$ up to $100 \mathrm{MHz}$. A laser with Qswitching produces the so-called giant pulses in the nanosecond or picoseconds range, as the mode-locked laser produces ultrashort pulses in the subpicosecond or femtosecond range with a high repetition rate. In dependence of technology used, the form of pulses can be different: rectangular, triangle, or Gaussian.

To describe energetic properties of pulsed light, a few more characteristics, such as pulse energy $E_{p}$, peak power $P_{p}$ (power within the individual pulse) and average power $P_{\text {ave }}$ for a train of pulses are used:

$$
\begin{aligned}
& P_{p}=E_{p} / \tau_{p}, \\
& P_{\text {ave }}=E_{p} \times f_{p} .
\end{aligned}
$$

Coherent light that is typically produced by lasers is light in which the electromagnetic waves maintain a fixed phase relationship over a period of time, and in which the phase relationship remains constant for various points in the plane that is perpendicular to the direction of propagation. Coherence length of a light source characterizes the degree of temporal coherence of the emitted light,

$$
l_{c}=c \tau_{c}
$$

where $c$ is the light speed and $\tau_{c}$ is the coherence time, which is approximately equal to the pulse duration of the pulsed light source or inversely proportional to the wavelength bandwidth $\Delta \lambda$ of a $\mathrm{CW}$ light source, $\tau_{c} \sim \lambda^{2} /(c \Delta \lambda)$. More precisely, for a Gaussian shape of a light source spectral band

$$
l_{c}=\frac{2 \ln (2)}{\pi} \cdot \frac{\lambda^{2}}{\Delta \lambda}
$$

A single frequency $\mathrm{CW} \mathrm{He}-\mathrm{Ne}$ laser with a narrow bandwidth $\Delta \lambda=10^{-6} \mathrm{~nm}$ and wavelength $\lambda=632.8 \mathrm{~nm}$ has a coherence length $l_{c} \approx 180 \mathrm{~m}$; a multimode diode laser with $\Delta \lambda=30 \mathrm{~nm}$ and $\lambda=830 \mathrm{~nm}$ has $l_{c} \approx 10 \mu \mathrm{m}$. For a titanium-sapphire laser with $\lambda=820 \mathrm{~nm}$, the bandwidth may be as big as $140 \mathrm{~nm}$; therefore, coherence length is very short $l_{c} \approx 2 \mu \mathrm{m}$. The shortest $l_{c}$ $\approx 0.9 \mu \mathrm{m}$ is for a white light source $(\Delta \lambda=400 \mathrm{~nm})$ or 
even $l_{c} \approx 0.2 \mu \mathrm{m}$ for the supercontinuum radiation with $\Delta \lambda=1500 \mathrm{~nm}$ from a microstructured fibre induced by a femtosecond titanium-sapphire laser with mean wavelength of $800 \mathrm{~nm}$. Coherence length is a fundamental parameter for optical coherence tomography (OCT); lower the $l_{\mathrm{c}}$ value, the better is the image resolution that can be achieved. OCT systems based on a femtosecond titanium sapphire laser or a supercontinium-based light source allows one to image skin with a subcellular resolution of $0.2-2 \mu \mathrm{m}$.

Polarized light is also used in tissue examination, thus its interaction specificity with tissues and cells should be accounted for [20].

\section{Biological tissues}

\subsection{General definitions and characteristics}

Biological tissue is an aggregate of similar cells and cell products (tissue fibres and gels) forming a definite kind of structural material in normal or abnormal state [47, 51, 66-76]. There are three major types of tissues, such as epithelial, connective, and glandular. More specifically tissues characterized as areolar, reticular, fibrous, tubular, and elastic. Tissues are also could be identified as belonging to a specific organ or system, i.e., mucosal, muscular, nervous, cervical, eye, skin, lymphoid, and adipose (fat), or to pathology state, i.e., scar tissue and malignant tissue.

Based on morphology, tissues can be also grouped into four basic types: epithelium, connective tissue, muscle tissue, and nervous tissue. Epithelial tissues are formed by layers of cells that cover organ surfaces such as the surface of the skin, the airways, and the inner lining of the digestive tract. Connective tissue is comprised of cells separated by nonliving material, which is called the extracellular matrix. There are the following five types of connective tissues: loose connective, dense connective, elastic, reticular, and adipose. Bone, cartilage, and blood belong to category of "specialized connective tissue." Muscle tissues are active contractile tissues of the body formed by muscle cells and separated into three distinct categories: smooth muscle, which is found in the inner linings of organs; skeletal muscle, which is found attached to bone providing for gross movement; and cardiac muscle that is found in the heart, allowing it to contract and pump blood throughout an organism. Cells comprising the central nervous system and peripheral nervous system are classified as neural tissue.

In general, tissue fibres are long strands of scleroprotein, which are either collagen-forming white fibres or elastin-forming yellow fibres, or reticulinforming reticular fibres. Tissue fibres, formed and maintained by fibroblasts, form part of a noncellular matrix around and among cells. A matrix may consist of an amorphous, jellylike polysaccharide together with these three types of fibre. Cells and a matrix form a connective tissue. Different forms of connective tissue possess varying proportions of the constituents of the matrix.

Areolar tissue is a soft, sometimes spongelike connective tissue that consists of an amorphous polysaccharide-containing and jellylike ground matrix with the embedded a loose network of white, yellow, and reticulin fibres. In this tissue, fibroblasts form and maintain the matrix. The areolar tissue is found all over the body, binding together organs (by mesenteries) and muscles (by sheaths), and occurring as subcutaneous tissue which function is to support or fill in the space between organs or between other tissues.

Reticular tissue is a tissue consisting of a network of reticular intercellular fibres around and among cells, with lymph in the intercellular spaces. They occur in many large organs, such as the liver, kidney and the larger glands, and in nerves and muscles. Reticular fibres are very thin, almost inextensible threads of reticulin - a tough fibrous protein. It is similar to collagen, but more resistant to high temperature and chemical reagents. Reticulin is forming in embryos and in wounds and often changes to collagen.

Fibrous tissue is a tissue mainly consisting of conjunctive collagen (or elastin) fibres, often packed in lamellar bundles or fascicles. In fibrous tissues or tissues containing fibre layers (cornea, sclera, dura mater, muscle, myocardium, tendon, cartilage, vessel wall, retinal nerve fibre layer (RNFL), etc.) and composed mostly of fibrils/subfibrils/microfibrils (or protofibrils) (Fig. 2), typical diameters of the cylindrical structural elements are 5-400 $\mathrm{nm}$; their length is in a range from $10-25 \mu \mathrm{m}$ to a few millimetres. Fibril is a fine fibre or filament, e.g., in muscles their diameters are in the range of 5-15 nm with a length of about 1-1.5 $\mu \mathrm{m}$ and in the eye cornea, their diameters are in the range of 26-30 nm with a mean length up to a few millimetres [74, 76].

Collagen is a tough, inelastic, fibrous protein. On boiling, it forms gelatine and, on adding acetic acid, it swells up and dissolves. Collagen in its turn forms white fibres in connective tissue. The tropocollagen or "collagen molecule" subunit is a rod about $300 \mathrm{~nm}$ long and $1.5 \mathrm{~nm}$ in diameter, made up of three polypeptide strands. There is some covalent crosslinking within the triple helices, and a variable amount of covalent crosslinking between tropocollagen helices, to form the different types of collagen found in different mature tissues. A distinctive feature of collagen is the regular arrangement of amino acids in each of the three chains of these collagen subunits.

There are a number of collagen types, which are different in their composition and structure, type I to type V are the most abundant; types I, II, III, V,VII and XI are capable of fibril formation; their distribution in tissues: type I - dermis, bone, cornea, tendon, cartilage, vessel wall, intestine, dentin, uterine wall, fat mashwork; type II - cartilage, notochord, vitreous humour, nucleus pulposus; type III - dermis, intestine, gingiva, heart valve, uterine wall, vessel wall; type IV and VII - basement membranes; type V - cornea, 
placental membranes, bone, vessel wall, cartilage, gingiva, and type XI - cartilage, intervertebral disc, vitreous humour [47]. In optical measurements collagen index of refraction is of importance, for example, for type I it is $n=1.43$ (fully hydrated) and 1.53 (dry) at $850 \mathrm{~nm}$ [77].

Collagen fibrils are collagen molecules packed into an organized overlapping bundle. In their turn, collagen fibrils associated in a bigger bundle form a collagen or white fibre - the main component of white fibrous tissue. For example, for tendon collagen, fibrils diameters are in the range from $\sim 25$ to $600 \mathrm{~nm}$ with bigger size for mature tendons, subfibrils are of $\sim 25 \mathrm{~nm}$, and protofibrils are in the range 10-15 nm (Fig. 2).

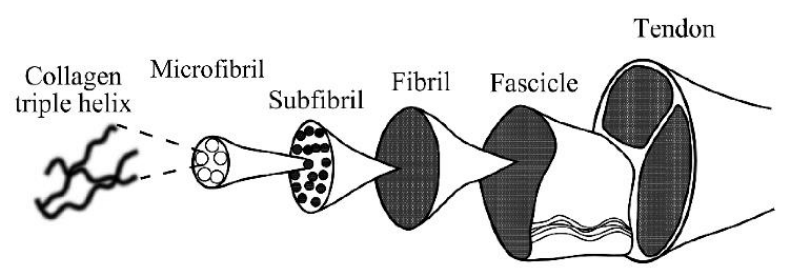

Fig. 2 Collagenous fibrillar structure in tendons: collagen triple helices are combined into microfibrils (or protofibrils), then into subfibrils, fibrils, fascicles and into tendons [72].

Yellow elastic tissue is a connective tissue that consists of a matrix of coarse yellow elastic fibres. Elastin, an elastic fibrous protein resistant to boiling and to acetic acid, is the principal constituent of this tissue formed and maintained by fibroblasts. The tissue rarely occurs pure and usually contains white fibres as well. Yellow elastic fibres are numerous in the lungs and in the walls of arteries, where elastic supporting tissues are required. Yellow elastic tissue occurs in ligaments, where an extensible tissue is required. Ligament is a band of fibrous tissue serving to connect bones, hold organs in place, etc.

Biological cell is an individual unit of protoplasm surrounded by a plasma membrane and usually containing a nucleus. A cell may exhibit all the characteristics of a living organism, or it may be highly specialized for a particular function. Cells vary considerably in size and shape, but all have the common features of metabolism. Most mammalian cells have diameters in the range of 5-75 $\mu \mathrm{m}$. For example, in the skin epidermal layer, the cells are large (with an average cross-sectional area of about $80 \mu^{2}$ ) and quite uniform in size; fat cells, each containing a single lipid droplet that nearly fills the entire cell and therefore results in eccentric placement of the cytoplasm and nucleus, have a wide range of diameters from a few microns to 50-75 $\mu \mathrm{m}$ [47].

There is wide variety of structures within cells that determine tissue light scattering. Cell nuclei are on the order of 5-10 $\mu \mathrm{m}$ in diameter; mitochondria, lysosomes and peroxisoms have dimensions of $1-2 \mu \mathrm{m}$; ribosomes are on the order of $20 \mathrm{~nm}$ in diameter; and structures within various organelles, such as mitochondria, can have dimensions up to a few hundred nanometers [47, 78](Fig. 3). Usually, the particles in cells are not spherical; the models of prolate ellipsoids with a ratio of the ellipsoid axes between 2 and 10 are typical.

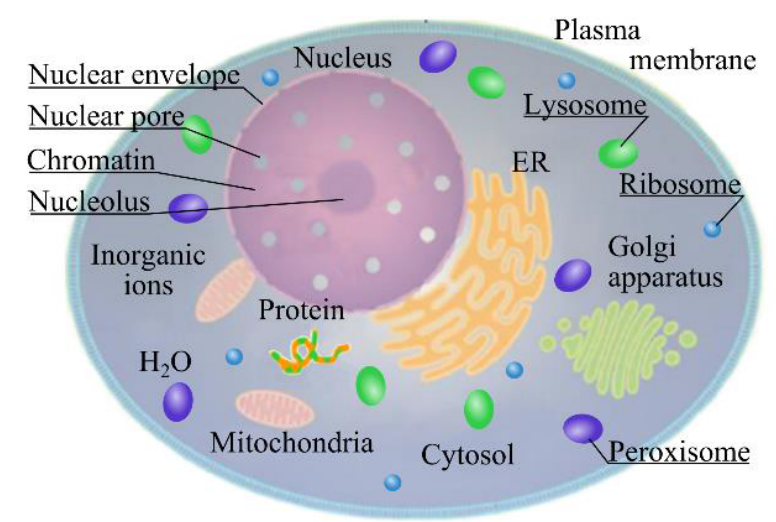

Fig. 3 Major organelles and inclusions of the cell: nucleus (chromatin, nuclear envelope, nuclear pore, nucleolus), mitochondria, lysosomes and peroxisoms, ribosomes, endoplasmic reticulum (ER), Golgi apparatus.

The hollow organs of the body are lined with a thin, highly cellular surface layer of epithelial tissue, which is supported by underlying, relatively acellular connective tissue. In healthy tissues, the epithelium often consists of a single, well-organized layer of cells with en-face diameter of 10-20 $\mu \mathrm{m}$ and height of $25 \mu \mathrm{m}$ [47](Fig. 4). In dysplastic epithelium, cells proliferate and their nuclei enlarge and appear darker (hyperchromatic) when stained. Enlarged nuclei are primary indicators of cancer, dysplasia and cell regeneration in most human tissues.

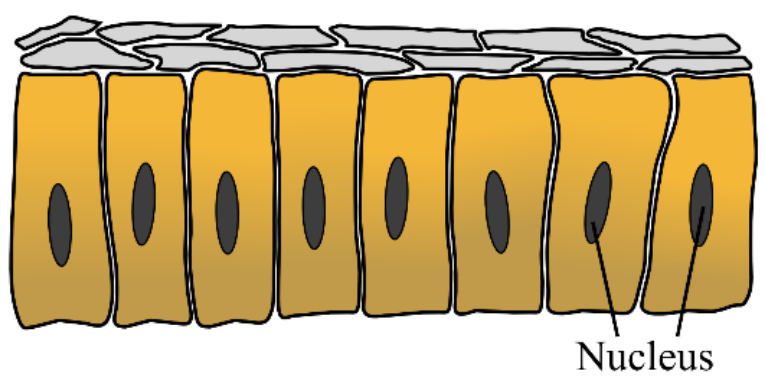

Fig. 4 One of the epithelial tissue types - a thin wellorganized cellular surface layer by which the hollow organs of the body are lined.

\subsection{Soft tissues}

A soft (antonym to hard) tissue has its structural peculiarities and elasticity providing the specificity of light-tissue interaction. Tissue morphology, especially sizing and shaping of tissue constitutions (particles), and particle material (molecular structure) are important. For some tissues, the size distribution of the particles may be essentially monodispersive and for others it may be very broad. Two opposite examples are optically 
transparent eye corneal stroma with a sharply monodispersive distribution of collagen fibre diameters, and turbid eye sclera with a rather broad distribution [74, 79-85].

Epithelial tissue is a tissue consisting of a sheet of epithelial cells held together by a minimal amount of cement-like material between the cells. It covers exposed surfaces and lines the cavities and tubes of the body. Beneath most epithelial tissue is a thin sheet of connective tissue - the basement membrane which separating epithelia from tissues below. Besides its protective function, epithelial tissue frequently has a secretory function, in which case it is known as glandular tissue. Keratinized epithelium structured to withstand abrasion. Keratin, a protein produced by mature epithelial cells called keratinocytes.

Mucous membrane (mucosa) is a membrane consisting of moist epithelium and the connective tissue immediately beneath it. It usually consists of simple epithelium, but is stratified near openings to the exterior. It is often ciliated and often contains goblet cells. Mucosa is found in the lining of the gastrointestinal and respiratory tracts, and in the urinogenital ducts. It is kept moist by glandular secretions.

Skin is the largest human organ. It covers between 1.5 and $2 \mathrm{~m}^{2}$, comprising about one sixth of total body weight. It has barrier function against the environment and provides human body response to environment condition change $[1,68,71,86]$. For example, skin protects us from water loss, ultraviolet rays of the sun, friction and impact wounds. It also helps in regulating body temperature and metabolism. Skin has three functional layers: epidermis, dermis, and hypodermis. The structures and component chromophores of these layers determine the attenuation of radiation in skin. In all three layers the epidermal appendages, such as nails, hair, and glands can be found. As the outermost skin layer, the epidermis forms the actual protective covering against environmental influences. It is a stratified epithelium that varies relatively little in thickness over most of the human body (between 75 and $150 \mu \mathrm{m}$ ) (Fig. 5), except on the face, where it may be as thin as $20 \mu \mathrm{m}$, and on the palms and soles of the feet, where its thickness may be thick as 400-5000 $\mu \mathrm{m}$. The epidermis consists of up to $90 \%$ keratinocytes, which function as a barrier, keeping harmful substances out and preventing water and other essential substances from escaping the body. The other $10 \%$ of epidermal cells are melanocytes, which manufacture and distribute melanin, the protein that adds pigment to skin and protects the body from ultraviolet radiation. The epidermis is conventionally subdivided into stratum basale, a basal cell layer of keratinocytes, which is the germinative layer of the epidermis, the stratum spinosum, which consists of several layers of polyhedral cells lying above the germinal layer, the stratum granulosum, which is a layer of flattened cells containing distinctive cytoplasmic inclusions, keratohyalin granules, and the overlying stratum corneum, consisting of lamellae of anucleate thin, flat squames that are terminally differentiated keratinocytes. Besides body site, epidermal thickness is related to age, gender, skin type, pigmentation, and blood content. The mean thickness of the stratum corneum is $\sim 18 \mu \mathrm{m}$ at the dorsal aspect of the forearm, $\sim 11 \mu \mathrm{m}$ at the shoulder, and $\sim 15 \mu \mathrm{m}$ at the buttock. The corresponding values for the living cellular epidermis consist of stratum granulosum, stratum spinosum, and stratum basale (Fig. 5), are $\sim 57 \mu \mathrm{m}, 70$ $\mu \mathrm{m}$, and $81 \mu \mathrm{m}$, respectively. For example, for thin skin at the shoulder, its layers are typically ranged from top to down as the following: $11 \mu \mathrm{m}$ for the stratum corneum, $23 \mu \mathrm{m}$ - the stratum granulosum, $30 \mu \mathrm{m}$-the stratum spinosum, and $17 \mu \mathrm{m}$ - the stratum basale [47].

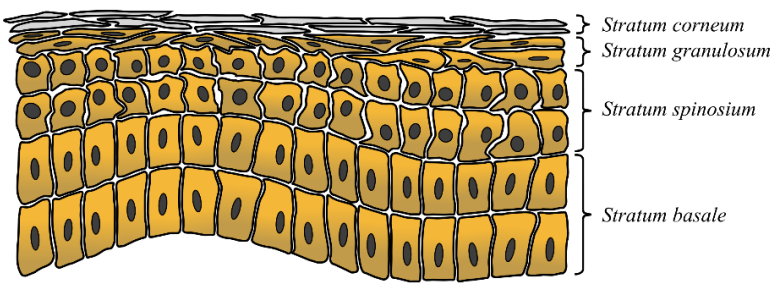

Fig. 5 Skin epidermis (epithelial layer) structure.

Due to different content of dark pigment - melanin, the tone of human skin can vary from a dark brown to a nearly colourless pigmentation, which may appear reddish due to the blood in the skin. Europeans generally have lighter skin, hair, and eyes than any other group. Africans generally have darker skin, hair, and eyes. For practical purposes, such as exposure time for sun tanning or phototherapy, six skin types are distinguished following Fitzpatrick, listed in order of decreasing lightness: I - very light, or "nordic" or "celtic" (often burns, rarely tans, tends to have freckles), II - light, or light-skinned European (usually burns, sometimes tans), III - light intermediate, or darkskinned European (rarely burns, usually tans), IV - dark intermediate, also "Mediterranean" or "olive skin" (rarely burns, often tans), V - dark or "brown" type (naturally brown skin), and VI - very dark, or "black" type (naturally black-brown skin) [1, 68, 71, 86].

Dermis is composed of gel-like and elastic materials, water, and, primarily, collagen (Fig. 6). Collagen fibres are abundant in the dermis and run parallel to the surface of the skin, they give the skin elasticity. The dermis is much thicker than the epidermis. The upper dermis layer is a papillary dermis. Reticular layer of dermis (reticular dermis) is the lower layer of the dermis. It is made primarily of coarse collagen and elastic fibres and is denser than the upper papillary dermis. It strengthens the skin, providing structure and elasticity. It also supports other skin componentsappendages such as sweat glands, hair follicles, and sebaceous glands. Lymph channels, blood vessels, nerve fibres, and muscle cells are also embedded in this layer.

The hypodermis consists of spongy connective tissue interspersed with energy-storing adipocytes (fat cells). Fat cells are grouped together in large cushionlike clusters held in place by collagen fibres called 
connective tissue septa or sheaths. The hypodermis is heavily interlaced with blood vessels, ensuring a quick delivery of stored nutrients as needed.

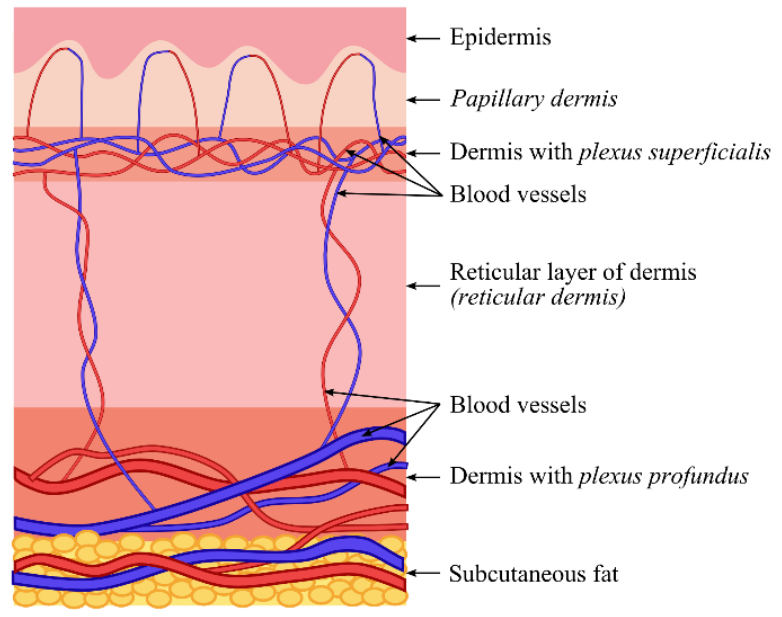

Fig. 6 Schematic representation of layered skin and subcutaneous fat.

In general, the adipose tissue is a modification of areolar tissue in which globules of oil are deposited in adipocytes. The cells occur, besides under the skin, around the abdominal organs (kidneys, liver, etc.). This tissue making in norm of $15-20 \%$ from weight of a body at men and $20-29 \%$ at women is a metabolically active "organ" supervised by neuroendocrine system. The adipose tissue of the subject consists of $60-85 \%$ of lipids, of $5-30 \%$ of water and of $2-3 \%$ of proteins [87]. Adipocyte is a cell in which a food reserve is deposited in the form of droplets of oil. The quantity of oil increases until the oil globule formed distends the cell and pushes the nucleus and cytoplasm to one side. A collection of fat cells forms adipose tissue. Fat occupies almost total volume of a fatty cell as the cell nucleus small and is located at its edge. In the different subjects the cell size is in the range $15-250 \mu \mathrm{m}$ with mean lipid content in a cell $0.3-1.2 \mathrm{mg}$ lipid/cell, and total number of cells of $(0.2-10) \times 10^{10}$. A great mass of lipids in fat tissue are neutral fats, or triglycerides (90-99\%), the rest are diglycerides and monoglycerides (1-3\%), phospholipids and glycolipids $(0.5-3 \%)$, free fat acids and cholesterol $(0.5-1.7 \%)$. The spaces between fat cells are occupied by small capillaries and interstitial fluid.

Muscular tissue is characterized by its ability to contract on being stimulated by a motor nerve. There are three main types of muscular tissue forming three types of muscles: striped muscle, unstriped muscle, and cardiac muscle. Myocard (myocardium) is the muscular tissue of the heart. It consists mostly of cardiac muscle which is comprised of myofibrils (about $1 \mu \mathrm{m}$ in diameter that in turn consist of cylindrical myofilaments of 6-15 $\mathrm{nm}$ in diameter) and aspherical mitochondria $(0.1-0.2 \mu \mathrm{m}$ in diameter). Fibres in myocardium are oriented along two different axes. It is typically birefringent since the refractive index along the axis of the muscle fibre is different from that in the transverse direction.

The dominant scatterers in an artery are the fibres, the cells, or the subcellular organelles. Muscular arteries have three main layers. The inner intimal layer consists of endothelial cells with a mean diameter of less than 10 $\mu \mathrm{m}$. The medial layer consists mostly of closely packed smooth muscle cells with a mean diameter of 15-20 $\mu \mathrm{m}$ and small amounts of connective tissue, including elastin, collagen, and reticular fibres as well as a few fibroblasts. The outer adventitial layer consists of dense fibrous connective tissue that is largely made up of 1-12 $\mu \mathrm{m}$ in diameter collagen fibres and thinner, $2-3 \mu \mathrm{m}$ in diameter, elastin fibres. The cylindrical collagen and elastin fibres are ordered mainly along one axis, thus causing the tissue to be birefringent.

Another type of multilayered tissue in general similar to skin is woman cervical tissue consisting of the upper epithelial layer, basal layer (basal membrane), and stromal layer. However depending on the area of the cervix, the epithelium may be in one of two forms: squamous or columnar.

The gingival tissue (gums) also consists of the mucosal tissue that laying over the jawbone [78]. The gingival tissue is naturally transparent and rendered red in colour because of the blood flowing through tissue. It connected to the teeth and bone by way of the periodontal fibres and is divided in three portions: free gingiva which forms a cuff around tooth and is not attached to bone, attached gingiva which is connected to bone, and interdental papilla which is a pointed portion of gingiva between teeth. Healthy gingiva is characterized by pale to coral pink colour with some pigmentation in darker skinned individuals.

The pulp is a soft connective tissue at centre of tooth containing fibroblasts, collagen, blood vessels, nerves and dentin forming odontoblasts. The odontoblasts make more dentin to protect tooth under conditions of pulp insult, e.g. caries. The pulp provides tooth nutrition due to rich vascular supply.

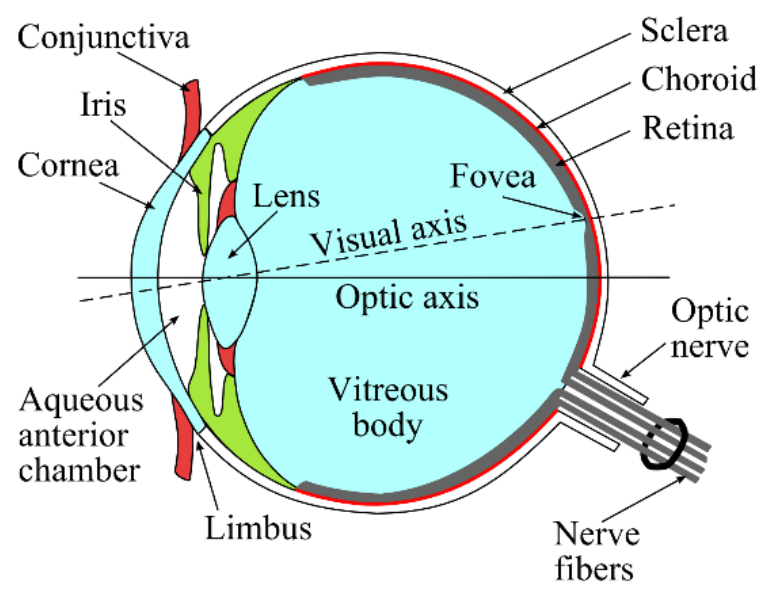

Fig. 7 Human eye structure and tissues.

Healthy tissues of the anterior human eye chamber (see Fig. 7), such as cornea and lens, are highly 
transparent for visible light because of their ordered structure and the absence of strongly absorbing chromophores in this wavelength range [74-76, 79-85]. The human cornea is the frontal section of the eye's fibrous capsule with diameter of about $10 \mathrm{~mm}$ and averaged thickness of $0.5 \mathrm{~mm}$. Its major layer constitutes $90 \%$ of the cornea's thickness is stroma, which is composed of several hundred successively stacked layers of lamellae (see Fig. 8, a-c), varied in width $(0.5-250 \mu \mathrm{m})$ and thickness $(0.2-0.5 \mu \mathrm{m})$ depending on the tissue region (electronic microscope images of three sequential lamellae are presented in Fig. 8 , a). Within each lamella, all of the fibres are nearly in parallel with each other and with the lamella plane. Fibrils are immersed into an amorphous ground (interstitial) substance containing water, glycosaminoglycans, proteins, proteoglycans, and various salts. The glycosaminoglycans play a key role in regulating the assembly of the collagen fibrils as well as in tissue permeability to water and other molecules. A few flat cells (keratocytes) are dispersed between lamellae, cells' total volume fraction is only $3-5 \%$ of the stromal volume. The fibrils in the human cornea have a uniform diameter of about $30.8 \pm 0.8 \mathrm{~nm}$ with a periodicity close to two diameters, i.e., $55.3 \pm 4.0 \mathrm{~nm}$, and rather high regularity in the organization of fibril axes about one another (see Fig. 8, a,c). The intermolecular spacing is of $1.63 \pm 0.10 \mathrm{~nm}$ [79-85]. Thus, corneal stroma has at least three levels of structural organization: the lamellae that lie parallel to the cornea's surface, the fibrillar structure within each lamella that consists of small, parallel collagen fibrils with uniform diameters with a high degree of shortrange spatial order, and the collagen molecular ultrastructure.

The sclera is a dense, white, fibrous membrane, which together with the cornea forms the external covering of the eyeball and serves as an eye protective membrane. It contains three layers: the episclera, the stroma and the lamina fusca. The stroma is the thickest layer of the sclera. In the scleral stroma, the collagen fibrils exhibit a wide range of diameters, from 25 to 230 $\mathrm{nm}[47,82]$. The average diameter of the collagen fibrils increases gradually from about $65 \mathrm{~nm}$ in the innermost part to about $125 \mathrm{~nm}$ in the outermost part of the sclera. The mean distance between fibril centres is about $285 \mathrm{~nm}$. Collagen intermolecular spacing is similar to that in the cornea, in particular in bovine sclera, particularly, it is equal to $1.61 \pm 0.02 \mathrm{~nm}[83]$. The fibrils are arranged in individual bundles in a parallel fashion, but more randomly than in the cornea. Within each bundle, the groups of fibres are separated from each other by large empty lacunae randomly distributed in space [82]. Collagen bundles show a wide range of widths ( 1 to $50 \mu \mathrm{m})$ and thicknesses $(0.5$ to $6 \mu \mathrm{m})$ and tend to be wider and thicker toward the inner layers. These ribbon-like structures are multiply crosslinked, their length can be a few millimetres. They cross each other in all directions, but remain parallel to the scleral surface. The episclera has a similar structure, with more randomly distributed and less compact bundles than in the stroma. The lamina fusca contains a larger amount of pigments, mainly melanin, which are generally located between the bundles.

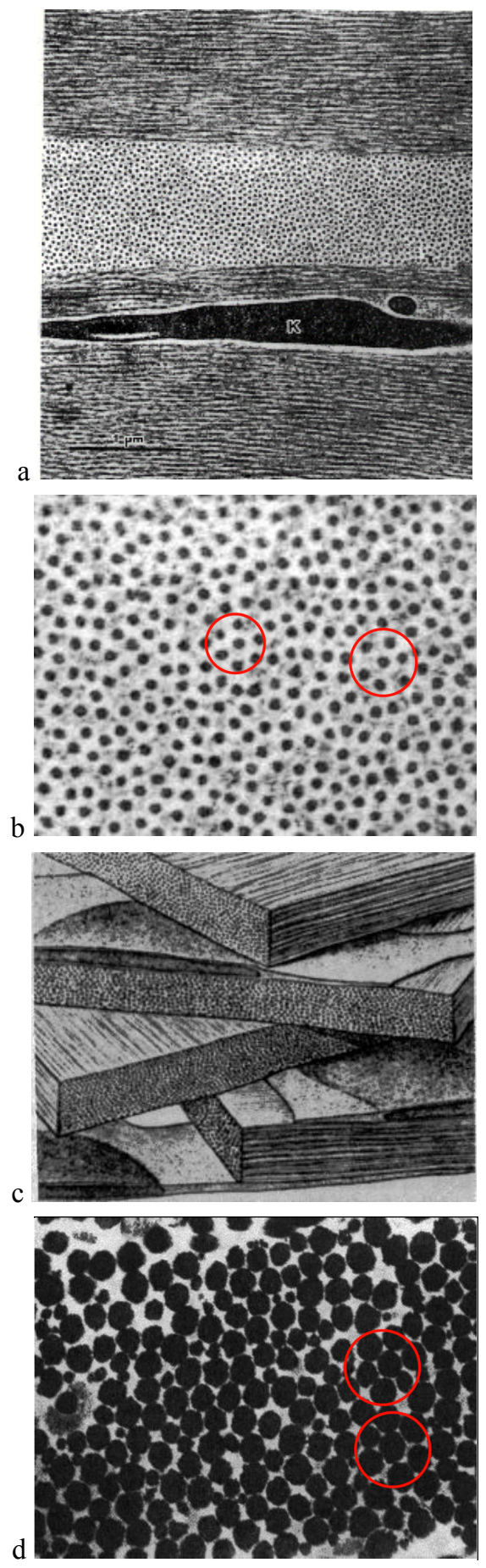

Fig. 8 The electron micrographs of the human cornea $(\times 32,000)$ collagen fibrils have a uniform diameter and are arranged in the same direction within the lamellae, $\mathbf{K}$ is the keratocyte, $\mathbf{b}$ - presents magnified image of middle lamella of image a; $\mathrm{c}$ - presents the model of lamellar-fibrillar structure of the corneal stroma; $d-$ presents scleral collagen fibrils, which display various diameters, however they are locally quasi-ordered [23, $58,82]$. 
The eye lens is also an example of a tissue in which the short-range spatial order is of crucial importance. Because of its high index of refraction and transparency, a lens focuses light to form an image at the retina (see Fig. 7). The eye lens material exhibits a certain viscosity that is capable of altering its radius of curvature and thus its focal length through the action of accommodating muscles. The healthy human lens is a structure containing about $60 \%$ of water and $38 \%$ of proteins. The lens consists of many fibre cells [88]. The predominant dry components of a mammalian lens are three kinds of structural proteins named $\alpha-, \beta-$, and $\gamma_{-}$ crystallins, and their combined weight accounts for about $33 \%$ of the total weight of the lens [89]. The primary role is played by the water-soluble $\alpha$ crystallin, which has a shape that is close to spherical with a diameter of about $17 \mathrm{~nm}$. Age-related biochemical endogenous processes in the organism and exogenous environmental-related stresses, such as photooxidation of lens proteins at chronic UV or visible light, resulting in oxidized forms of these proteins and their crosslinking to other lens proteins, cause lens opacity due to light scattering and/or pigment formation.

The types of fibre cell disruption at cataract formation include intracellular globules, clusters of globules, vacuoles with the contents wholly or partially removed, clusters of highly curved cell membranes, and odd-shaped domains of high or low mass density. These spherical objects are variable in size (often in the range 100 to $250 \mathrm{~nm}$ ) and occur in clusters that create potential scattering centres [88].

One more example of complex tissue structure is retinal nerve fibre layer (RNFL), which is formed by the expansion of the fibres of the optic nerve and comprises bundles of unmyelinated axons that run across the surface of the retina (see Fig. 7). Retina is the innermost coat of the posterior part of the eyeball that receives the image produced by the crystalline lens. It consists of several layers, one of which contains the rods and cones sensitive to light. The cylindrical organelles of the retinal nerve fibre layer are axonal membranes, microtubules, neurofilaments and mitochondria. Axonal membranes, like all cell membranes, are thin $(6-10 \mathrm{~nm})$ phospholipid bilayers that form cylindrical shells enclosing the axonal cytoplasm. Axonal microtubules are long tubular polymers of the protein tubulin with an outer diameter of $\approx 25 \mathrm{~nm}$, an inner diameter of $\approx 15 \mathrm{~nm}$, and a length of $10-25 \mu \mathrm{m}$. Neurofilaments are stable protein polymers with a diameter of $\approx 10 \mathrm{~nm}$. Mitochondria are ellipsoidal organelles that contain densely involved membranes of lipid and protein. They are $0.1-0.2 \mu \mathrm{m}$ thick and $1-2 \mu \mathrm{m}$ long.

The brain and spinal cord together make up the central nervous system. Grey matter is a nervous tissue found in the central nervous system. It contains numerous cell bodies, dendrites, synapses, terminal processes of axons, blood vessels and neuroglia. Brain nuclei and nerve centres are composed of grey matter and coordination in the central nervous system is effected in grey matter. White matter is also a nervous tissue found in the central nervous system. It consists of tracts of medullated nerve fibres in the brain and spinal cord and also contains blood vessels and neuroglia. It is mainly external to grey matter, but is internal to grey matter in the cerebral hemispheres and in the cerebellum. The medullated fibres give the tissue its shiny white appearance. The spinal cord is a long, thin, tubular bundle of nervous tissue and supporting cells that extends from the brain (the medulla specifically) down to the space between the first and second lumbar vertebrae. It is around $45 \mathrm{~cm}$ in men and around $43 \mathrm{~cm}$ long in women. The brain and spinal cord is protected by three layers of tissue, called spinal meninges, that surround them.

The dura mater is the outermost layer, and it forms a tough protective coating. Between the dura mater and the surrounding bone of the skull or vertebrae is a space, called the epidural space, which is filled with adipose tissue, and it contains a network of blood vessels. The arachnoid is the middle protective layer, the space between the arachnoid and the underlying pia mater contains cerebrospinal fluid (CSF). The pia mater is the innermost protective layer, which is very delicate and tightly associated with the surface of the brain and spinal cord.

Dura mater is the tough and inflexible two layered tissue. A superficial layer is actually the bone inner periosteum, and a deep layer is the dura mater proper. Dura mater proper consists of layers of densely packed collagen fibrils having an alternating orientation (see Fig. 9).

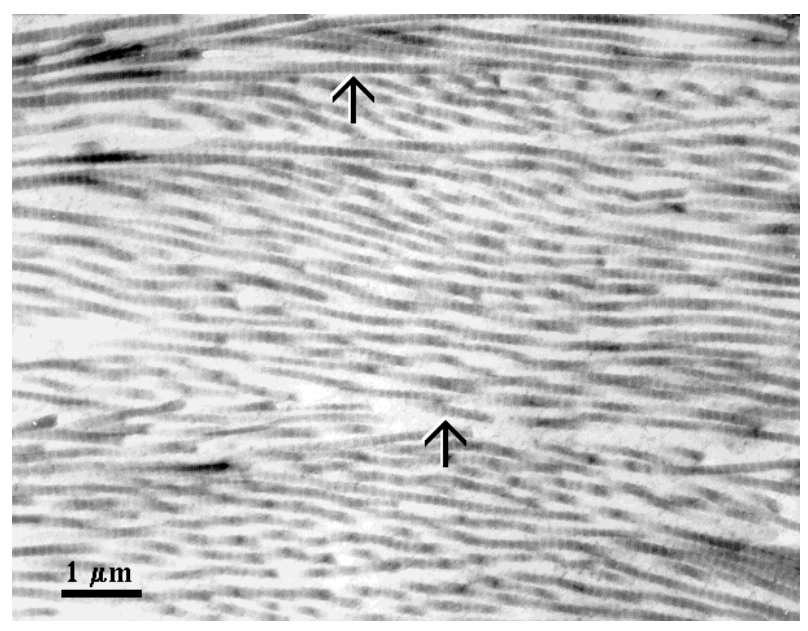

Fig. 9 Electronic micrograph of dura mater proper with layers of densely packed collagen fibrils having an alternating orientation and mean diameter of $\sim 100 \mathrm{~nm}$.

Tissue aging and pathology may dramatically change its structure and appearance. For example, scar tissue typically occupies areas of fibrous tissue that replace normal tissue (skin or other tissue) after injury [90, 91] (see Fig. 10). A scar results from the biologic process of wound repair. Thus, scarring is a natural part of the healing process. Other examples are benign or malignant tumours which are abnormally growing 
tissues sometimes well vascularised and having the tendency to spread to other parts of the body.

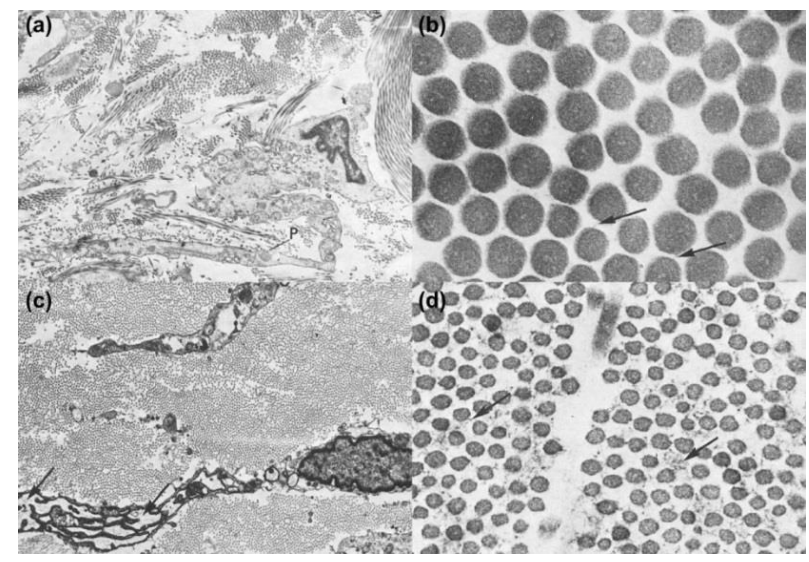

Fig. 10 Electronic micrographs of collagen fibers of normal skin (upper) [(a) and (b)] and nodule of a hypertrophic scar (down) [(c) and (d)] [magnification $\times 10,000$ for (a) and (c) and $\times 105,000$ for (b) and (d)] [90].

\subsection{Hard tissue}

The bone, tooth enamel, dentin, and cementum, as well as tendon and cartilage belong to hard tissue [22, 23, 40, 47, 58, 78, 92-99]. The bone, cartilage, and tendon are also connective tissues which typically consist of cells scattered in an amorphous mucopolysaccharide matrix in which there are varying amounts of connective tissue fibres (mainly collagen, but also elastin and reticulin).

In particular, the bone is a connective tissue forming the skeleton. It consists of cells embedded in a matrix of bone salts and collagen fibres. The bone salts (mostly calcium carbonate and phosphate, hydroxyapatite crystals) form about $60 \%$ of the mass of the bone and give it its tensile strength. Organic dry weight is $90 \%$ collagen which gives bone its elasticity and contributes to fracture resistance. In bone, entire collagen triple helices lie in a parallel, staggered array, with the $40 \mathrm{~nm}$ gaps between the ends of the tropocollagen subunits, which probably serve as nucleation sites for the deposition of long, hard, fine crystals of the mineral component - hydroxyapatite with some phosphate. In this way, certain kinds of cartilage turn into bone.

The apatite or hydroxyapatite (HAP) natural crystals, $\mathrm{Ca}_{5} \mathrm{OH}\left(\mathrm{PO}_{4}\right)_{3}$, is the major component of hard tissues. The dental enamel consists of $87-95 \%$ and bone of $50-60 \%$ of HAP crystals.

The osseous cells are interconnected by fine protoplasmic processes situated in narrow channels in the bone, and are nourished by the blood stream. This vascular nature of bone differentiates it from cartilage. The flexible tissue found in the hollow interior of bones is the bone marrow. Throughout life, all bones are in a dynamic process of growth and resorption called "remodelling." This allows the bone to adapt to changing mechanical forces and the body's need for calcium balance. The osteoblasts are mononucleate cells that are responsible for bone formation - reshaping.
The demineralization process is the loss of mineral from mineralized tissues such as bone or tooth. In tooth tissue, demineralization may lead to caries, in bone - to osteoporosis. For example, bacteria in tooth plaque use carbohydrates such as sucrose and glucose in human diet for their metabolic needs and produce lactic acid during the breakdown of these substrates. In its turn, lactic acid can demineralize the tooth hard tissue. The demineralization of outermost tooth layers - enamel and cementum is the starting point of tooth destruction. However, small amounts of tooth demineralization occur daily - remineralization can be occur as mineral is replaced with calcium and phosphate from saliva.

The osteoporosis is a disease of bone causing an increased risk of fracture due to reduction of bone mineral density, which leads to bone microarchitecture disruption, and alteration of the amount and variety of non-collagenous proteins in bone.

As an example of bone structure, an alveolar bone that is a part of upper and lower jaws, which holds roots of teeth, is shown in Fig. 11, a [47, 78]. It consists of two parts: lamina dura (alveolar bone proper) - dense bone lining socket with inserted periodontal fibres, and supporting bone which is a remaining part of alveolar bone composed from highly mineralized (70\%) mostly calcium phosphate (hydroxyapatite) crystals, minor amounts of magnesium, sodium and potassium, osteoblasts and osteoclasts, collagen fibres, and proteoglycans.

The periodontal ligament is a fibrous connective tissue attachment anchoring tooth to surrounding bone. The collagen fibres are embedded on tooth side in cementum and on bone side in lamina dura. It mainly composed of collagen with minor amounts of elastin, and ground substance - proteoglycans and water. This tissue contains such cells as fibroblasts, osteoblasts and cementoblasts, immune cells (e.g., macrophages, lymphocytes), nerves and is supplied by blood via blood vessels.

Tooth is the hard body composed of dentin surrounding a sensitive pulp and covered on the crown with enamel (see Fig. 11, a). Crown is a portion of natural tooth visible in mouth above gumline. Tissue layers from outside in are enamel, dentin, and pulp. Root is a portion of tooth under gumline, anchoring tooth in bone, layers from outside in are cementum, dentin, and pulp.

The enamel is a hardest tissue in a body, elastic, white material that contains no cells and that is an almost completely inorganic substance. The enamel covers the crown of a tooth and consists of up to $95 \%$ of natural HAP crystals and rest are water and proteins. These crystals are organized in keyhole-shaped interlocking rods/prisms. The rods are formed as enamel forming ameloblasts migrate towards outer layer of tooth, once enamel is formed, ameloblasts die, thus if enamel is destroyed, it cannot be regenerated. These rods/prisms are 4-6 $\mu \mathrm{m}$ wide and extend from the dentine-enamel-junction to the outer surface of the tooth (see Fig.11). Because of their size, number, and 
refractive index, the prisms are the main light scatterers in enamel. The enamel is translucent and greyish white in colour and it has yellow hue due to underlying dentin.
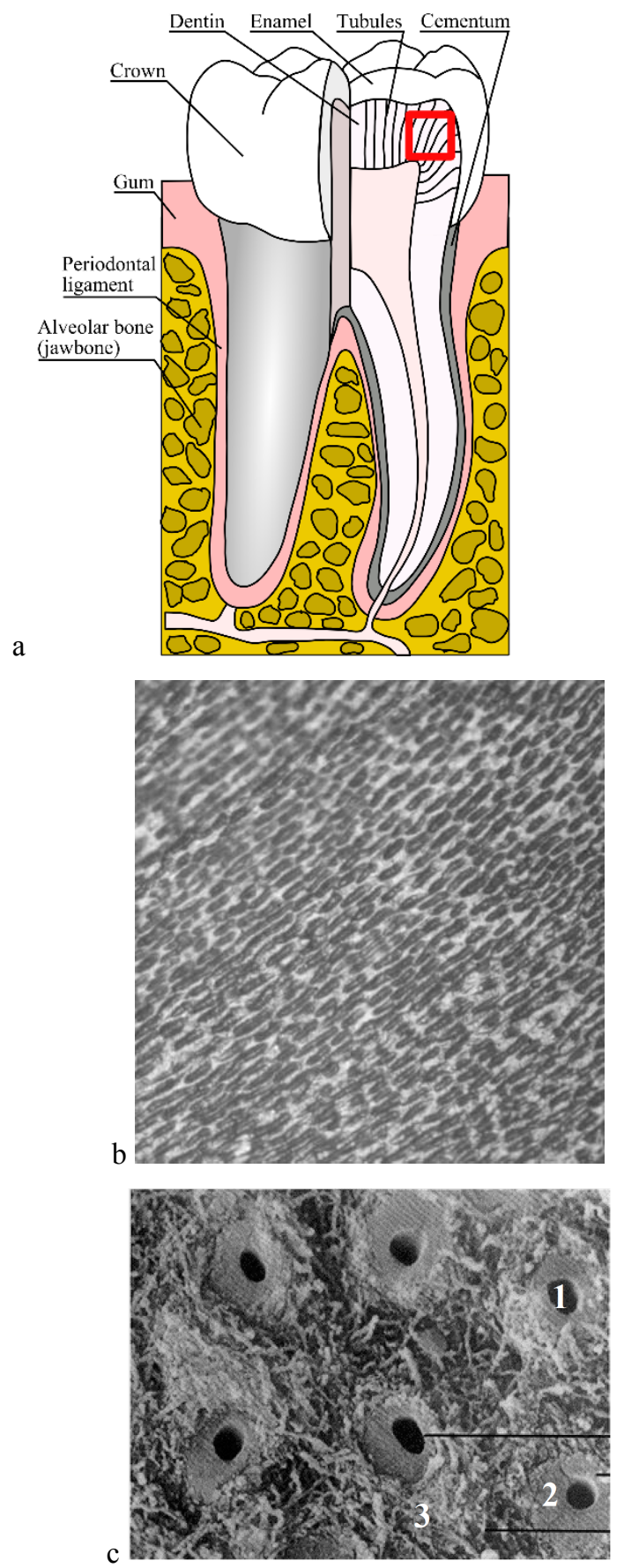

Fig. 11 Schematic representation of tooth structure, including dentinal channels - tubules (a); laser scanning microscopy image of dentinal tubules $(\sim 90 \times 90 \mu \mathrm{m})(\mathrm{b})$ [97]; electron scanning microgram of human dentin (presented by R. Vilar): (1) dentinal tubules, (2) dense and homogeneous pertubular dentin and (3) less dense and less homogeneous intertubular dentin (c).

The tooth dentin is a hard, middle calcified, elastic, yellowish material of the same substance as bone. It is the main structural part of a tooth extending from crown to root. The dentin is composed of base material that is pierced by mineralized dentinal tubules $1-5 \mu \mathrm{m}$ in diameter which makes it porous (see Fig.11, c). The tubules' density is in the range of $(3.0-7.5) \times 10^{6} \mathrm{~cm}^{-2}$. They contain organic components and natural HAP crystals of $2.0-3.5 \mathrm{~nm}$ in diameter and up to $100 \mathrm{~nm}$ in length, which intensively scatter light. In average dentin contains $70 \%$ HAP crystals, $20 \%$ proteins (e.g., collagen), and $10 \%$ water. It is softer than enamel but slightly harder than bone. Unlike enamel, dentin is living tissue - cells which form dentin (odontoblasts) lie at border of dentin and pulp during the life of tooth this gives dentin ability to grow and repair.

The tooth cementum is a thin, pale yellow, calcified bone-like layer covering root of tooth. It contains $45 \%$ HAP crystals, $55 \%$ protein (collagen) and water. It is softer than both dentin and bone. The cementum functions include coverage of the dentin tubules and insertion point of periodontal ligament fibres. It has ability to form throughout life of tooth cementoblasts which form cementum lie along root surface in periodontal ligament space.

The cartilage is a strong, resilient, skeletal tissue. There are a few types of cartilage, all of which contain chondroblasts depositing the matrix and becoming enclosed in the matrix as chondrocytes. The hyaline cartilage is the simplest and most common form that consists of a matrix of a polysaccharide-containing protein. The matrix is without structure and without blood vessels. It is more or less translucent and clear, and occurs in the cartilaginous rings of the trachea and bronchi. The yellow fibrocartilage (elastic cartilage) contains yellow fibres in the matrix. It occurs in the external ear and in the epiglottis. As well as white fibrocartilage contains white fibres in the matrix and occurs in the disks of cartilage between the vertebrae. Articular cartilage itself and cartilage-bone interface play a highly important role in normal function of joints by dissipating stresses and providing almost frictionless joint movement [94].

The tendon is a cord of white fibrous tissue. It usually attaches muscle to bones and consists mostly of parallel, densely packed collagen fibres arranged in parallel bundles interspersed with long, elliptical fibroblasts. In general, tendon fibres are cylindrical in shape with diameters ranging from 20 to $400 \mathrm{~nm}$. The ordered structure of collagen fibres running parallel to a single axis makes tendon a highly optically birefringent tissue [100].

\subsection{Tissue structural anisotropy}

As it follows from the analysis of tissue properties, many biological tissues are structurally anisotropic. Tissue birefringence results primarily from the linear anisotropy of fibrous structures, which forms the extracellular media. The refractive index of a medium is higher (speed of light is lower) along the length of fibres than along their cross section. A specific tissue structure is a system composed of parallel cylinders that create a uniaxial birefringent medium with the optic axis parallel 
to the cylinder axes. This is a so-called birefringence of form (Fig. 12). A large variety of tissues such as eye cornea, tendon, cartilage, eye sclera, dura mater, muscle, myocardium, artery wall, nerve, retina, bone, teeth, myelin, etc. exhibit birefringence. All these tissues contain uniaxial and/or biaxial birefringent structures. For example, myocardium contains fibres oriented along two different axes. It consists mostly of cardiac muscle fibres arranged in sheets that wind around the ventricles and atria. Since the refractive index along the axis of the cardiac muscle fibres is different from that in the transverse direction, tissue is birefringent.

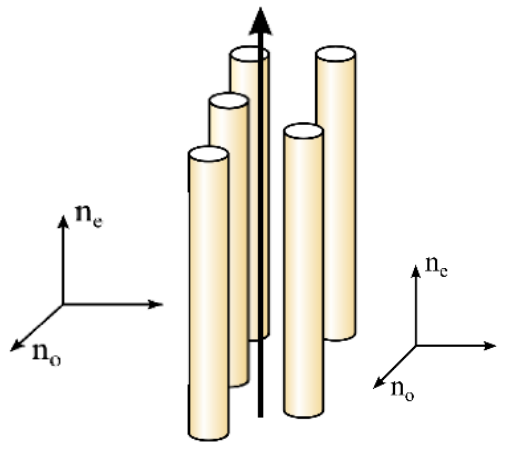

a

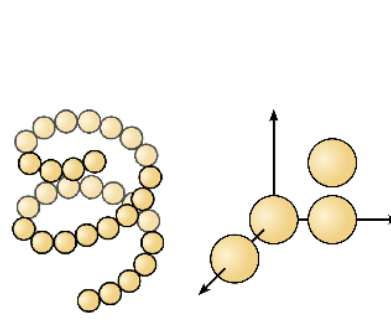

c

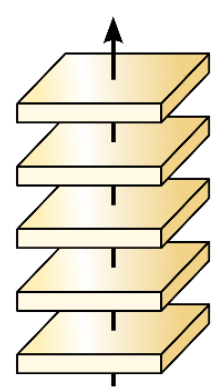

b

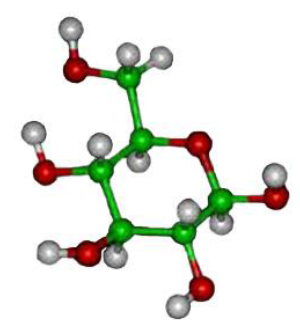

d
Fig. 12 Examples of structurally anisotropic models of tissues and tissue components: a - system of long dielectric cylinders; $b$ - system of dielectric plates; $c$ chiral aggregates of particles; d - glucose (chiral molecule) as a tissue component $[23,58]$.

Form birefringence arises when the relative optical phase between the orthogonal polarization components is nonzero for forward-scattered light. For linear structures, an increase in optical field phase delay $\left(\delta_{o e}\right)$ is characterized by a difference in the effective refractive index for light polarized along, and perpendicular to, the long axis of the linear structures $\left(\Delta n_{\mathrm{oe}}\right)$. Phase retardation $\delta_{\mathrm{oe}}$ between orthogonal polarization components, is proportional to the distance $d$ travelled through the birefringent medium $[23,58]$

$$
\delta_{o e}=\frac{2 \pi d \Delta n_{o e}}{\lambda_{0}}
$$

A structure of parallel dielectric cylinders immersed in isotropic homogeneous ground substance behaves as a positive uniaxial birefringent medium
$\left(\Delta n_{o e}=\left(n_{e}-n_{o}\right)>0\right)$ with its optic axis parallel to the cylinder axes (Fig. 12, a). Therefore, an incident electrical field directed parallel to the cylinder axes will be called "extraordinary ray" (e) and the incident electrical field perpendicular to the cylinder axes will be called "ordinary ray"(o). The difference $\left(n_{\mathrm{e}}-n_{\mathrm{o}}\right)$ between the indices of refraction of the extraordinary and ordinary rays is a measure of the birefringence of a medium. For the Rayleigh limit (diameter of cylinders $<<1$ ), the form birefringence is described as

$$
\Delta n_{o e}=\left(n_{e}-n_{o}\right)=\frac{f_{1} f_{2}\left(n_{1}-n_{2}\right)^{2}}{f_{1} n_{1}+f_{2} n_{2}},
$$

where $f_{1}$ is the volume fraction of the cylinders; $f_{2}$ is the volume fraction of the ground material; and $n_{1}, n_{2}$ are the corresponding indices. For a given difference of refraction index $\left(n_{1}-n_{2}\right)$, maximal birefringence is expected for approximately equal volume fractions of thin cylinders and ground material. For systems with high volume fraction of cylinders or on the contrary ground material (rare fibres), the birefringence goes down.

The experimental birefringence for muscle, coronary artery, myocardium, sclera, skin, cartilage and tendon is in the range from $1.4 \times 10^{-3}$ to $4.2 \times 10^{-3}$. For these tissues, it is lowest for the muscle and highest for the tendon. For thermally treated tendon, it is twice lower than for intact tissue.

The diattenuation (linear dichroism) is the difference of attenuation of two waves with orthogonal polarizations travelling in an anisotropic medium, which is described by the difference between the imaginary (losses) parts of the effective indices of refraction for two orthogonal directions. Depending on the relationship between the sizes and the optical properties of the cylinders or plates, this difference can take positive or negative values.

The birefringence and diattenuation relate to the density and some other properties of the collagen fibres, whereas the orientation of the fast axis indicates the orientation of the collagen fibres. The densities of collagen fibres in skin and cartilage are not as uniform as in tendon, and the orientation of the collagen fibres is not distributed as orderly as in tendon. Correspondingly, the amplitude and orientation of birefringence of the skin and cartilage are not as uniformly distributed as in tendon.

In addition to linear birefringence and diattenuation, many tissue components show optical activity (circular birefringence) and circular diattenuation. In complex tissue structures, chiral aggregates of particles may be responsible for tissue optical activity (see Fig. 12, c). The molecule's chirality, which stems from its asymmetric molecular structure (see Fig. 12, d), also results in a number of effects generically called optical activity. A well-known manifestation of optical activity is the ability to rotate the plane of linearly polarized light about the axis of propagation. The amount of rotation depends on the chiral molecular concentration, the pathlength through the medium, and the light 
wavelength. Interest in tissue chirality studies is driven by the potential of noninvasive in situ optical monitoring of the glucose in diabetic patients.

More sophisticated anisotropic tissue models can also possible. For example, the eye cornea can be represented as a system of plane anisotropic layers (plates, i.e., lamellas), each of which is composed of densely packed long cylinders (fibrils) (see Fig. 8, c) with their optical axes oriented along a spiral. This fibrilar-lamellar structure of the cornea is responsible for the linear and circular diattenuation and its dependence on the angle between the lamellas.

In bone and tooth, anisotropy is due to mineralized structures originating from hydroxyapatite crystals, which play an important role in hard tissue birefringence. In particular, dental enamel is an ordered array of such crystals surrounded by a protein/lipid/water matrix. Fairly well oriented hexagonal crystals of hydroxyapatite of approximately $30-40 \mathrm{~nm}$ in diameter and up to $10 \mu \mathrm{m}$ in length are packed into an organic matrix to form enamel prisms (or rods) with an overall cross section of 4-6 $\mu \mathrm{m}$. Enamel prisms are roughly perpendicular to the tooth surface (see Figs. 11 and 13). Tooth dentin is a complex structure, honeycombed with dentinal tubules, which are shelled organic cylinders with a highly mineralized shell.

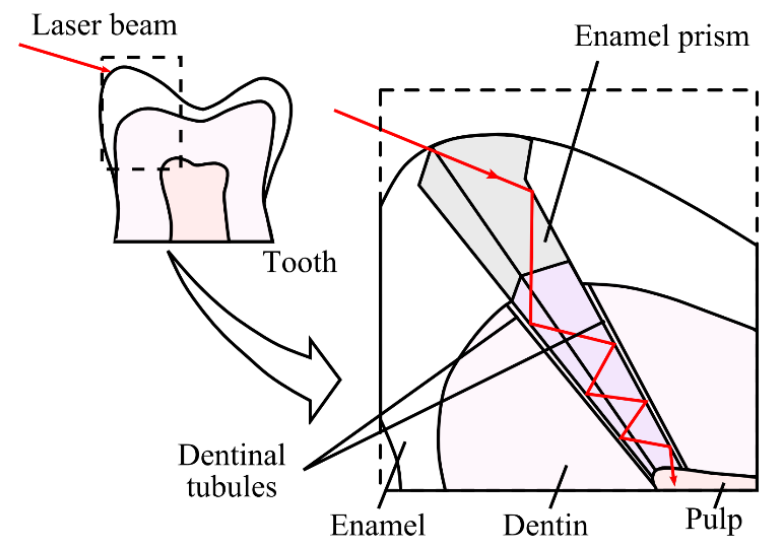

Fig. 13 Schematic representation of laser beam waveguiding in human tooth tissues [97].

Enamel and dentin waveguide properties also may have effects on anisotropy of light transportation within a tooth. The role of waveguides in enamel and dentin is played by enamel prisms and intertubular butt straps, respectively (Fig. 13). These waveguides are distinguished from conventional optical fibers by being nonuniform and containing scattering particles, such as hydroxyapatite microcrystals. However, they have waveguide properties and radiation scattered in enamel and dentin can be entrapped by these natural waveguides and transported to the pulp chamber.

\subsection{Blood, lymph and other bioliquids}

The blood is a fluid tissue contained in a network of vessels or sinuses in humans and animals. Blood is circulating through the network by muscular action of the vessels or the heart to transport oxygen, metabolites, and hormones. It also assists in temperature control in mammals [23, 47, 58, 101-103].

Blood contains soluble colloidal proteins (blood plasma) and blood corpuscles (blood cells) such as red blood cells (RBCs) (erythrocytes), white blood cells (WBCs) (leukocytes), and platelets (thrombocytes). Normally, blood has about 10 times as many erythrocytes as platelets and about 300 times as leukocytes. There are approximately five million per cubic millimetre RBCs in normal human blood.

A normal erythrocyte in plasma has the shape of a concave-concave disc with a diameter varying from 7.1 to $9.2 \mu \mathrm{m}$, a thickness of $0.9-1.2 \mu \mathrm{m}$ in the centre and $1.7-2.4 \mu \mathrm{m}$ on the periphery, and a volume of $90 \mu \mathrm{m}^{3}$. Platelets in the blood stream are biconvex disk-like particles with diameters ranging from 2 to $4 \mu \mathrm{m}$. Leukocytes are formed like spheres with a diameter of 8-22 $\mu \mathrm{m}$.

The platelets are small, non-nucleated, round or oval disks that are fragments of cells from red bone marrow. There are approximately 200,000-400,000 per $\mathrm{mm}^{3}$ platelets in human blood. These cells initiate blood clotting by disintegrating and releasing thrombokinase.

WBCs are nucleated, motile, colourless cells found in the blood and lymph of animals. A WBC is either a lymphocyte, a polymorph, or a monocyte. In humans, there are approximately 8000 leukocytes per cubic millimetre. A lymphocyte is a spherical WBC with one large nucleus and relatively little cytoplasm. Two types exist, small and large lymphocytes which are produced continually in lymphoid tissues, such as lymph nodes, by cell division. The cells are nonphagocytic, exhibit amoeboid movement, and produce antibodies in the blood. They constitute about $25 \%$ of all leukocytes in the human body. A monocyte is a spherical WBC with an oval nucleus. The monocytes are the largest of the WBCs. The cells are voraciously phagocytic and exhibit amoeboid movement. They are produced in lymphoid tissues and constitute about $5 \%$ of all leukocytes.

The relative volume of the RBCs in blood expressed in percentages is named hematocrit (Hct). It also can be presented as packed cell volume (PCV) or erythrocyte volume fraction (EVF). Hct is normally about $48 \%$ for men and 38\% for women and independent of body size and considered as an integral part of a person's complete blood count results.

To provide the main function of $\mathrm{RBC}$ to carry oxygen and carbon dioxide away from and towards the lung, cell contains a respiratory pigment, haemoglobin. The cell is readily distorted, elastic, and immotile. Mammalian RBCs have no nuclei. They are formed in red bone marrow and after a relatively short life span (in average 120 days in humans) are destroyed by erythrophages. RBC index of refraction is of 1.4 in the wavelength range 600 to $1100 \mathrm{~nm}$.

The haemoglobin is a red iron-containing respiratory pigment. It consists of haeme combined with globin, a blood protein and conveys oxygen to the tissues. The 


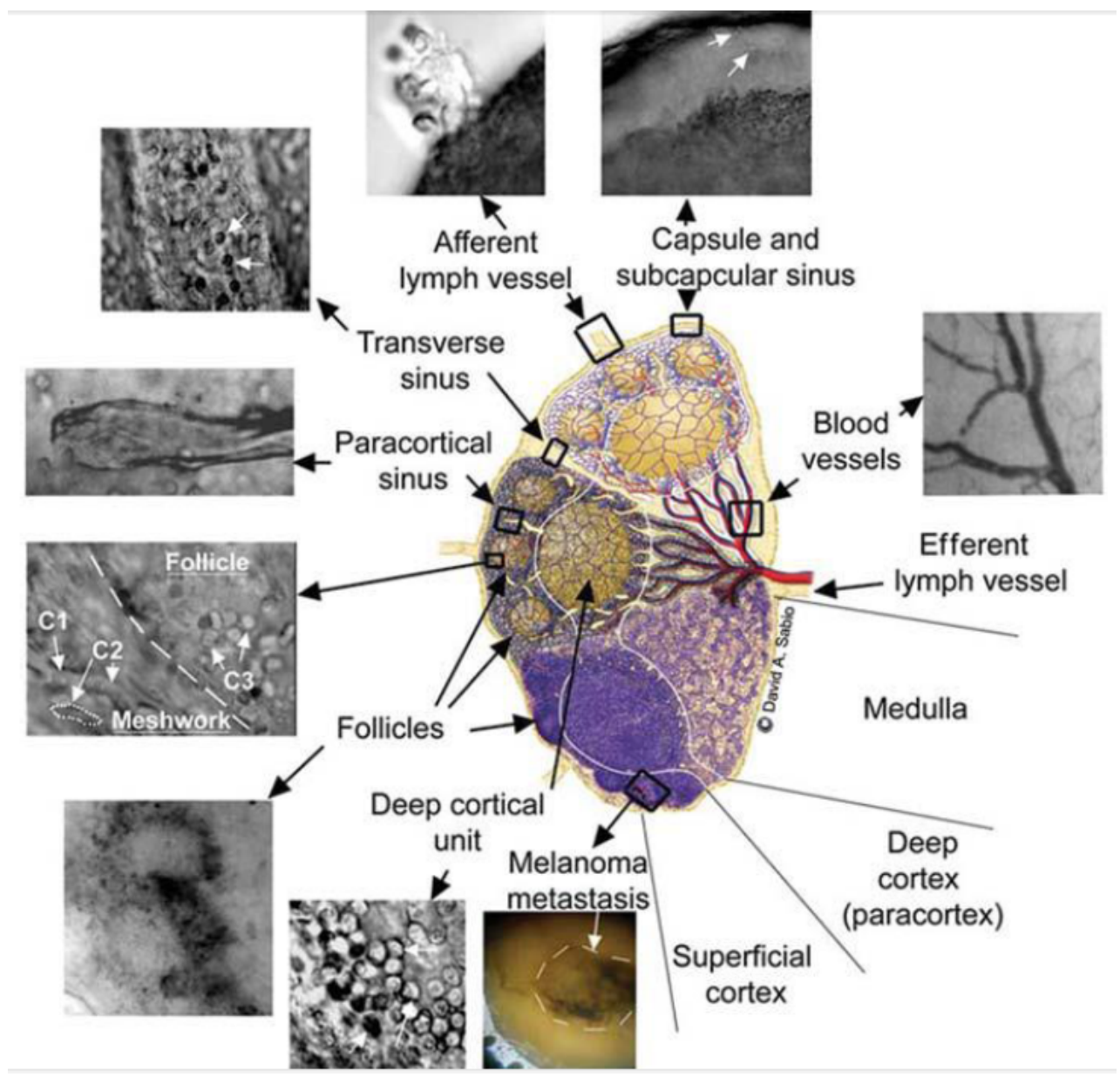

Fig. 14 The schematics of microanatomy of a lymph node designed by David Sabio presenting a midsagital section of a lymph node containing three lymphoid lobules with the basic anatomical and functional units, including superficial cortex, deep cortex and medulla, is shown (drawing in the centre). Experimental transillumination digital images of afferent lymph vessel, subcapsular, transverse, and paracortical sinuses, deep cortical unit, a reticular meshwork, follicles, and the venous vessels around central schematics are also shown: C1 presents likely basophilic lymphocytes; C2 - elongated fibroblastic reticular cells, and C3 - B lymphocytes and follicular dendritic cells; melanoma metastasis is seen in the back reflectance image [104].

haemoglobin occurs in reduced form (deoxyhaemoglobin, $\mathrm{Hb}$ ) in venous blood and in combination with oxygen (oxyhaemoglobin, $\mathrm{HbO}_{2}$ ) in arterial blood. The total haemoglobin (THb) is the sum concentration of the oxy- and deoxyhaemoglobin.

Oxyhemoglobin dissociation ability is described by dissociation curve that characterizing the relationship between oxygen partial pressure $\mathrm{pO}_{2}$ and oxygen saturation $\left(\mathrm{SaO}_{2}\right)$. Normally about $97 \%$ of the oxygen is carried by haemoglobin whereas only $3 \%$ is carried dissolved in the blood. As the $\mathrm{pO}_{2}$ increases, the amount of oxygen that is bound to haemoglobin, or the percent saturation of haemoglobin, also increases. The saturation of haemoglobin of about $50 \%$ and $97 \%$ is normally achieved at a $\mathrm{pO}_{2}$ of about $26.6 \mathrm{mmHg}$ and 95 $\mathrm{mmHg}$, respectively, and the saturation point, $\mathrm{SaO}_{2}$, at $\mathrm{pO}_{2}=80 \mathrm{mmHg}$. In the capillaries normally the haemoglobin is about $75 \%$ saturated and the blood delivers about $5 \mathrm{ml}$ of oxygen per $100 \mathrm{ml}$ of blood to the tissues. In tissues haemoglobin oxygen saturation is calculated as $\mathrm{SaO}_{2}=\left(\mathrm{HbO}_{2} / \mathrm{THb}\right) \times 100 \%$.
The carboxyhemoglobin $(\mathrm{COHb})$ is a stable complex of carbon monoxide and haemoglobin (bright, cherry red in colour) that forms in RBCs when carbon monoxide is inhaled or produced in normal metabolism. Because haemoglobin binds with carbon monoxide 240 times more readily than with oxygen, large quantities of it hinder delivery of oxygen to the body.

The blood plasma is the clear, waterlike, colourless liquid of blood which is formed by removing all blood corpuscles from blood.

The blood vessel is a tube through which blood flows either to or from the heart. The general terms for conducting vessels for blood are arteries, veins, arterioles, venules, and capillaries.

For in vitro microscopic examination of blood a well prepared blood smear is necessary. The simple wedge technique for preparation of blood smears is often applied. This simple technology is used to determine leukocyte differentials, to evaluate erythrocyte, platelet and leukocyte morphology, and, if necessary, to estimate platelet and leukocyte counts. This technique 
produces a gradual decrease in thickness of the blood from thick to thin ends with the smear placed on the slide. In typical preparations, the thin section of the smear occupies approximately $1 / 3$ of the total area and, within that area erythrocytes are distributed in a monolayer. Glass coverslips are mounted on all blood smears to prevent damage to smear during examination, cleaning, handling and storage.

The lymph in the organism is an alkaline colourless liquid obtained from blood by filtration through pores in the walls of capillaries. It contains a smaller amount of soluble blood proteins and WBCs than blood, but more lymphocytes. Normally it contains no RBCs. The lymph travels to at least one lymph node before emptying ultimately into the right or the left subclavian vein, where it mixes back with blood. The lymph that leaves a lymph node is richer in lymphocytes, as the lymph formed in the digestive system called chyle is rich in triglycerides (fat), and looks milky white. The lymph function is to bathe the cells with water and nutrients.

The lymphatic system is a network which includes the lymphoid tissue and lymphatic vessels through which the lymph travels in one-way toward the heart as well as all the structures providing the circulation and production of lymphocytes $[103,104]$. Lymph is formed when interstitial fluid enters the initial lymphatic vessels of the lymphatic system which transport lymph back to the blood, ultimately replacing the volume lost during the formation of the interstitial fluid. In contrast to the cardiovascular system, the lymphatic system is not closed and has no central pump. The lymph transport, therefore, is slow and sporadic, like a shuttle-stream, and occurs due to alternate contraction and relaxation of smooth muscles, valves, and compression during contraction of adjacent skeletal muscle and arterial pulsation. The study of lymphatic drainage of various organs is important in diagnosis, prognosis, and treatment of cancer. The lymphatic system, because of its physical proximity to many tissues of the body, is responsible for carrying cancerous cells between the various parts of the body in a process called metastasis. The intervening lymph nodes can trap the cancer cells (sentinel lymph node). If they are not successful in destroying the cancer cells, the nodes may become sites of secondary tumours.

The lymphoid tissue is a part of the lymphatic system and consists of connective tissue with various types of WBCs enmeshed in it, most numerous being the lymphocytes. The thymus and the bone marrow constitute the primary lymphoid tissues involved in the production and early selection of lymphocytes. The secondary lymphoid tissues are the lymph nodes, and the lymphoid follicles in tonsils, spleen, adenoids, skin, etc.

The lymphatic vessels (lymphatics) are thin-walled tubular vessels resembling veins in structure but with thinner walls and more valves. The walls are enclosed by smooth muscle and connective tissue. Lymphatic vessels drain into lymph ducts. The lymphatic vessels act as channels along which pathogens are conducted from infected areas of the body, the pathogens being unable to enter the blood capillaries. The lymph nodes are distributed along the lymphatic vessels.

The cerebrospinal fluid (CSF) is the clear liquid that fills the cavities of the brain and spinal cord and the spaces between the arachnoid and pia matter. The fluid moves in a slow current down the central canal and up the spinal meninges. It is a solution of blood solutes of low molar mass, such as glucose, but of the smaller concentration $(60-80 \%)$ as in the blood. The CSF contains little or no protein and very few cells. Its function is to nourish the nervous tissue and to act as a buffer against shock to the nervous tissue. At any one time in an adult, the average volume of CSF is about $150 \mathrm{ml}$.

The saliva is a viscid, colourless, watery fluid secreted into the mouth by the salivary glands and composed from water (99\%), mucin, bicarbonate, proteins, and minerals. It functioning as lubricator to protect mucosa, it assists in formation of food bolus for effective swallowing, in initial enzymatic breakdown of some food components, antimicrobial protection, buffering, and tooth enamel remineralization. There are 3 major salivary glands and hundreds of minor salivary glands in the oral cavity. The amount of saliva produced varies widely - in healthy individuals it ranges from 0.5 $-1.5 \mathrm{~L}$ daily.

The mucus is a thin, slimy, viscous liquid secreted by epithelial cells in tissues or glands. It protects and lubricates the surface of structures, e.g., the internal surfaces of the greater part of the alimentary canal are lubricated with mucus.

The tear film on the surface of the eye also has some diagnostic potential due to correlation of tear and blood glucose concentrations [105]. It is composed of several layers. Most superficially there is a lipid layer that is less than $100 \mathrm{~nm}$ thick which serves several functions including preventing evaporation of the underlying aqueous layer and providing a smooth optical surface over the cornea. The lipid layer is composed of sterol esters, wax esters, and many other minor lipid components secreted from the Meibomian glands located on the margins of the eyelids. Dysfunction of these glands can lead to increased evaporation of tears from the eye, causing an increased tear osmolarity and clinical dry eye. Just below the lipid layer is a predominantly aqueous layer. Measurements of the thickness of this layer over the cornea varies from 2.7 $\mu \mathrm{m}$ to $46 \mu \mathrm{m}$.

\subsection{Conclusion}

This is the first section of the review-tutorial paper describing fundamentals of tissue optics and photonics mostly devoted to biological tissue structures and their specificity related to light interactions at its propagation in tissues. The next sections of the paper will describe light-tissue interactions caused by tissue dispersion, scattering, and absorption properties, including light reflection and refraction, absorption, elastic quasielastic and inelastic scattering. The major tissue 
absorbers and types of elastic scattering, including Rayleigh and Mie scattering, will be presented.

Basing on the random phase screen concept, scattering of the coherent light and speckle formation principles will be discussed. Speckle interferometry and low-coherent light interferometry - optical coherence tomography (OCT), will be described.

Dynamic light scattering method as a powerful approach for functional spectroscopy and imaging of living tissues will be analysed. Fundamentals of quasielastic light scattering (QELS), Doppler anemometry, and dynamic speckle techniques and their applications to blood and lymph flow measurements, including fullfield velocity mapping, will be discussed. Principles of diffusion wave spectroscopy and imaging, interaction of the polarized light with tissues for random and quasiordered tissues will be presented. Comparison of single and multiple scattering approaches, as well as description of refractive index matching concept for controlling of light interaction with tissues, will be done.

\section{Acknowledgments}

I am thankful to Valery Zakharov for his idea to write such a paper, to all my colleagues from SSU and IPMC RAS for fruitful collaboration, and to Alexander Kalyanov for help in preparation of illustrations. This work was supported by Russian Presidential grant NSh703.2014.2, the Government of the Russian Federation grant 14.Z50.31.0004, and the Ministry of Education and Science of the Russian Federation 